
Aliados

\author{
Takahashi, J. A.; ${ }^{*}$ Lima, G. S.; dos Santos, G. F.; Lyra, F. H.; da Silva- \\ Hughes, A. F.; Gonçalves, F. A. G.
}

Rev. Virtual Quim., 2017, 9 (6), 2351-2382. Data de publicação na Web: 21 de setembro de 2017

http://rvq.sbq.org.br

\title{
Filamentous Fungi and Chemistry: Old Friends, New Allies
}

\begin{abstract}
Fungi are classically associated with problems such as deterioration and contamination of foods, human mycoses and diseases that bring damage to agriculture. However, the biotechnological potential of these organisms surpasses enormously their potential damage and the number of fungal species with importance in chemistry, pharmacology, environment, ecology, agriculture and food is extraordinary. In this field, the chemistry helped understanding fermentation processes and fungal metabolism, increasing the use of processes using fungal metabolites. The chemistry has also helped to control the presence of fungi when they are unwanted, providing preservatives and antioxidants for food and cosmetics, antimycotic agents and antifungals for agricultural use. However, the interdisciplinarity of the fungal metabolism study has brought new and interesting challenges. This review will address important aspects on cultivation, identification, use and biotechnological potential of fungi and their metabolites from the perspective of their historical use. Then current aspects of the use of fungi for the benefit of human life, as for the development of new drugs, environmental and ecological applications such as using bioremediation, in addition to presenting new frontiers for research, as the search for fungi in new habitats, the use of challenging growing conditions for elicitation of metabolic production and the use of modern analytical techniques to enlarge the biotechnological application of fungi will be presented.
\end{abstract}

Keywords: Fungi; secondary metabolites; biotransformation; bioremediation; applications.

\section{Resumo}

Os fungos são classicamente associados a problemas como a deterioração e contaminação de alimentos, micoses humanas e doenças que trazem prejuízos à agricultura. Entretanto, o potencial biotecnológico destes organismos supera enormemente os potenciais danos e o número de espécies fúngicas com importância química, farmacológica, ambiental, ecológica, agrícola e alimentícia é extraordinário. Neste campo, a química ajudou a entender os processos fermentativos e o metabolismo fúngico, potencializando as aplicações de processos e metabólitos fúngicos. A química também tem ajudado a controlar a presença de fungos quando a mesma é indesejada, fornecendo agentes conservantes para alimentos e cosméticos, antioxidantes, antimicóticos e antifúngicos para uso agrícola. No entanto, a interdisciplinaridade do estudo do metabolismo fúngico tem trazido novos e interessantes desafios. Nesta revisão serão abordados aspectos importantes sobre o cultivo, identificação, utilização e potencial biotecnológico de fungos e seus metabólitos partindo da perspectiva do seu uso histórico. Em seguida, serão apresentados aspectos atuais da utilização de fungos para benefício da vida humana, como o desenvolvimento de novos fármacos, aplicações ambientais e ecológicas como o uso de biorremediação, além de se apresentar novas fronteiras para a pesquisa, como a busca de fungos em novos habitats, o uso de condições de cultivo desafiadoras para elicitação da produção metabólica e o uso de técnicas analíticas modernas para ampliar a aplicação biotecnológica de fungos.

Palavras-chave: Fungos; metabólitos secundários; biotransformação; biorremediação; aplicações.

\footnotetext{
* Universidade Federal de Minas Gerais, Instituto Ciências Exatas, Departamento de Química, CEP 31270-901, Belo Horizonte-MG, Brazil.

Miat@qui.ufmg.br

DOI: $\underline{10.21577 / 1984-6835.20170141}$
}

Rev. Virtual Quim. |Vol 9| | No. 6| |2351-2382| 


\title{
Fungos Filamentosos e Química: Velhos Conhecidos, Novos Aliados
}

\author{
Jacqueline A. Takahashi, ${ }^{\mathrm{a}, *}$ Gesiane da S. Lima, ${ }^{\mathrm{a}}$ Gabriel F. dos Santos, ${ }^{\mathrm{a}}$ \\ Fernanda H. Lyra, ${ }^{a}$ Alice F. da Silva-Hughes, ${ }^{a}$ Flávia A. G. Gonçalves ${ }^{b}$ \\ ${ }^{a}$ Universidade Federal de Minas Gerais, Instituto Ciências Exatas, Departamento de Química, \\ CEP 31270-901, Belo Horizonte-MG, Brazil. \\ ${ }^{\mathrm{b}}$ Centro Federal de Educação Tecnológica de Minas Gerais, Departamento de Química, CEP \\ 30421-169, Belo Horizonte-MG, Brazil. \\ * jat@qui.ufmg.br
}

Recebido em 27 de abril de 2017. Aceito para publicação em 12 de setembro de 2017

\section{Introdução}

2. Uso histórico e contemporâneo de fungos como alimentos

\subsection{Cogumelos}

3. Fungos e a produção de metabólitos secundários bioativos

4. Isolamento e caracterização de metabólitos secundários bioativos

5. Aplicação de fungos para a biotransformação de produtos naturais e fármacos

6. Biorremediação

7. Conclusão e perspectivas

\section{Introdução}

Fungos filamentosos têm sido utilizados para a produção de medicamentos $\mathrm{e}$ alimentos, resolução de racematos, processos fermentativos e degradação natural de resíduos ambientais há tempos. Os processos químicos associados a este uso são bem conhecidos e a importância industrial e ecológica dos fungos é inegável. Da produção de antibióticos, medicamentos que revolucionaram o estilo e a expectativa de vida humana, até a fabricação de queijos como Camemberti e Roqueforti, a química e a microbiologia andaram juntas para 0 entendimento dos processos químicos e bioquímicos e para o aperfeiçoamento das tecnologias envolvidas. No entanto, o potencial do uso de fungos em química, para trazer opções mais sustentáveis ou ocupar nichos ainda inocupados, embora grande, é desconhecido ou, pelo menos, ainda pouco estudado. Como aliados, os fungos podem ajudar a resolver problemas difíceis para a química, como a funcionalização de carbonos não ativados, a remoção sustentável de poluentes em áreas contaminadas e a produção de novos fármacos. Por outro lado, a química tem ajudado na identificação de 
fungos e de seus complexos metabólitos, trazendo agilidade para a propecção da diversidade metabólica fúngica na busca de novas drogas. Nesta revisão, partindo de exemplos bem estabelecidos, procuraremos mostrar novos avanços deste fascinante mundo de aplicações de produtos e metabólitos fúngicos e novas opções para a utilização destes importantes aliados na busca de uma química cada vez mais verde, iniciando por uma das aplicações mais antigas, que é o uso de fungos na área de alimentação. diversos da Terra. Os fungos vivem em diversos ambientes e sua dispersão na natureza ocorre por meio de agentes do ar e água, sementes, insetos, animais e seres humanos. A grande biodiversidade das espécies fúngicas reflete-se em suas características macroscópicas (Figura 1), em diferentes propriedades biológicas, em variados sistemas enzimáticos e em uma vasta produção metabólica. No Brasil são reconhecidas quase seis mil espécies de fungos, distribuídas em 1.246 gêneros, 102 ordens e 13 divisões. ${ }^{1}$

O Reino Fungi é um dos grupos mais

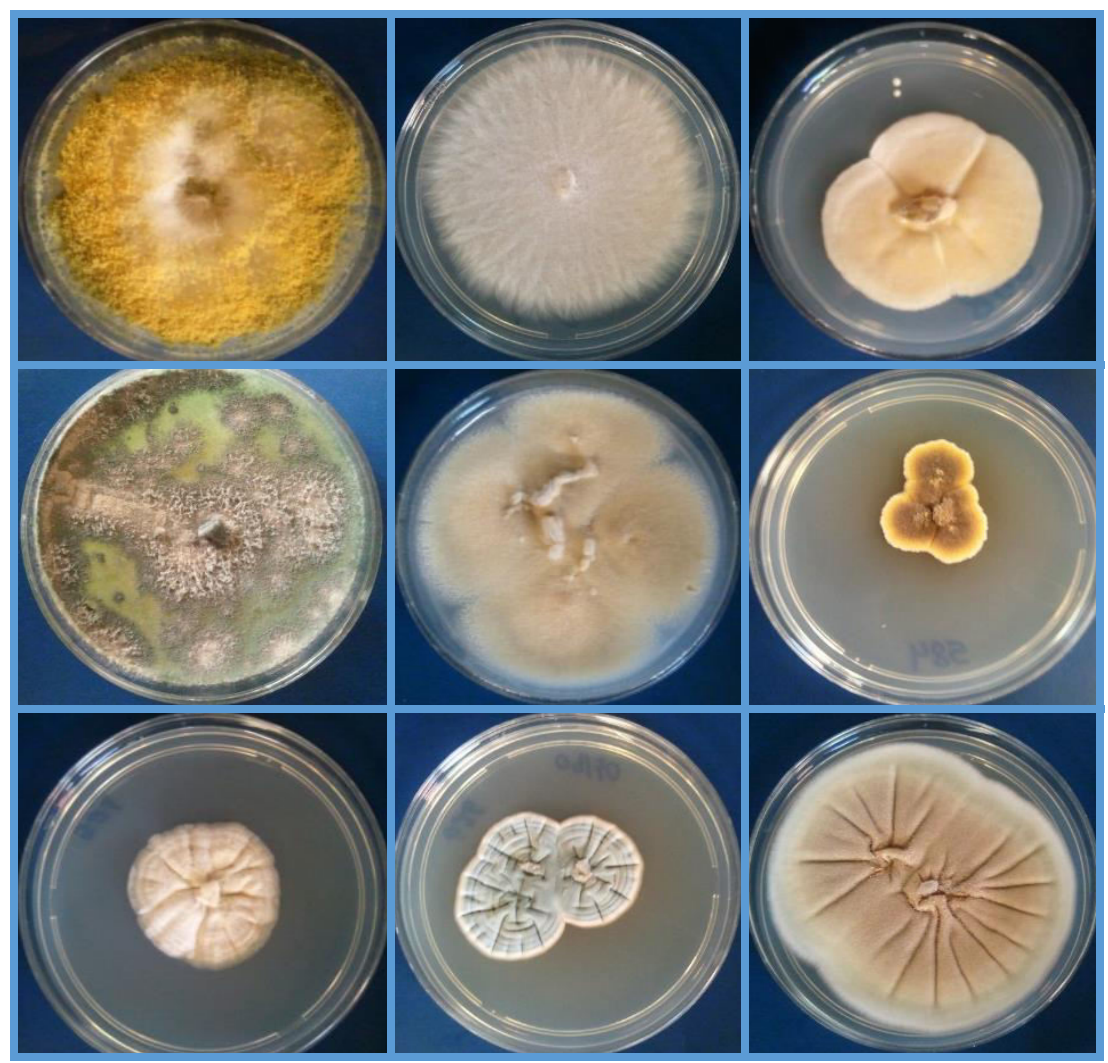

Figura 1. Diversidade morfológica de fungos filamentosos cultivados em ágar batata dextrose (BDA) por 7 dias, a $25^{\circ} \mathrm{C}$

Esse Reino é composto por leveduras, organismos unicelulares, e por fungos filamentosos (cogumelos e bolores), organismos multicelulares. As leveduras são esféricas, ovais ou cilíndricas. Os fungos filamentosos, por sua vez, formam massas visíveis a olho nu chamadas de micélio, compostas de longos filamentos chamados de hifas que se ramificam e se entrelaçam. Dentre os fungos filamentosos, encontram-se também os cogumelos, que possuem corpos de frutificação.

Em linhas gerais, os fungos possuem parede celular composta por glucanas e quitina, são organismos eucariotos uni ou multinucleados, sendo homo ou 
heterocarióticos, haploides, dicarióticos ou diploides. A reprodução pode ser sexual (cariogamia e meiose), parassexual (cariogamia seguida de aneuploidia) e/ou assexual (divisão nuclear mitótica). ${ }^{2}$ São quimio-heterotróficos, obtendo nutrientes por meio da absorção de compostos orgânicos como fontes de carbono e energia. Como esses organismos conseguem sobreviver à custa de grande variedade de compostos orgânicos, podem habitar diversos ambientes como solo, água do mar, água doce e viver associados a animais, insetos, plantas e detritos.

A classificação mais moderna dos fungos reconhece sete filos: Chytridiomycota, Blastocladiomycota, Neocallimastigomycota, Microsporidia, Glomeromycota, Ascomycota e Basidiomycota. Os grupos Ascomycota e Basidiomycota têm um ancestral comum exclusivo e, por isso, são mais próximos filogeneticamente do que os outros grupos. ${ }^{3}$ Alguns fungos apresentam características distintas quando se encontram no estágio assexuado (fungos anamórficos) e no estágio sexuado (teleomórficos). Por isso, nomes diferentes eram dados à mesma espécie, de acordo com o estágio em que se encontravam. Em 2011, o Código Internacional de Nomenclatura para Algas, Fungos e Plantas (Código de Melbourne ou ICN), adotou no XVIII Congresso Botânico Internacional de Melbourne (Austrália) o fim da nomenclatura dupla para as espécies de Ascomicetos e Basiodiomicetos.

A identificação dos fungos filamentosos é realizada principalmente por taxonomia clássica e por biologia molecular. No caso da taxonomia clássica, utilizam-se características morfológicas macroscópicas (superfície e o reverso da colônia, aspecto da borda, diâmetro, cor dos conídios e micélio, textura, presença de exudados e pigmentos solúveis, etc), microscópicas (forma e cor da hifa, presença ou não de septos, tipo e arranjo de esporos, etc.) (Figura 2) e velocidade de crescimento. A identificação taxonômica de leveduras é realizada avaliando-se caracteristicas fisiológicas, utilizando como critério a assimilação de fontes de carbono e nitrogênio e resistência/sensibilidade a agentes antifúngicos. ${ }^{4}$

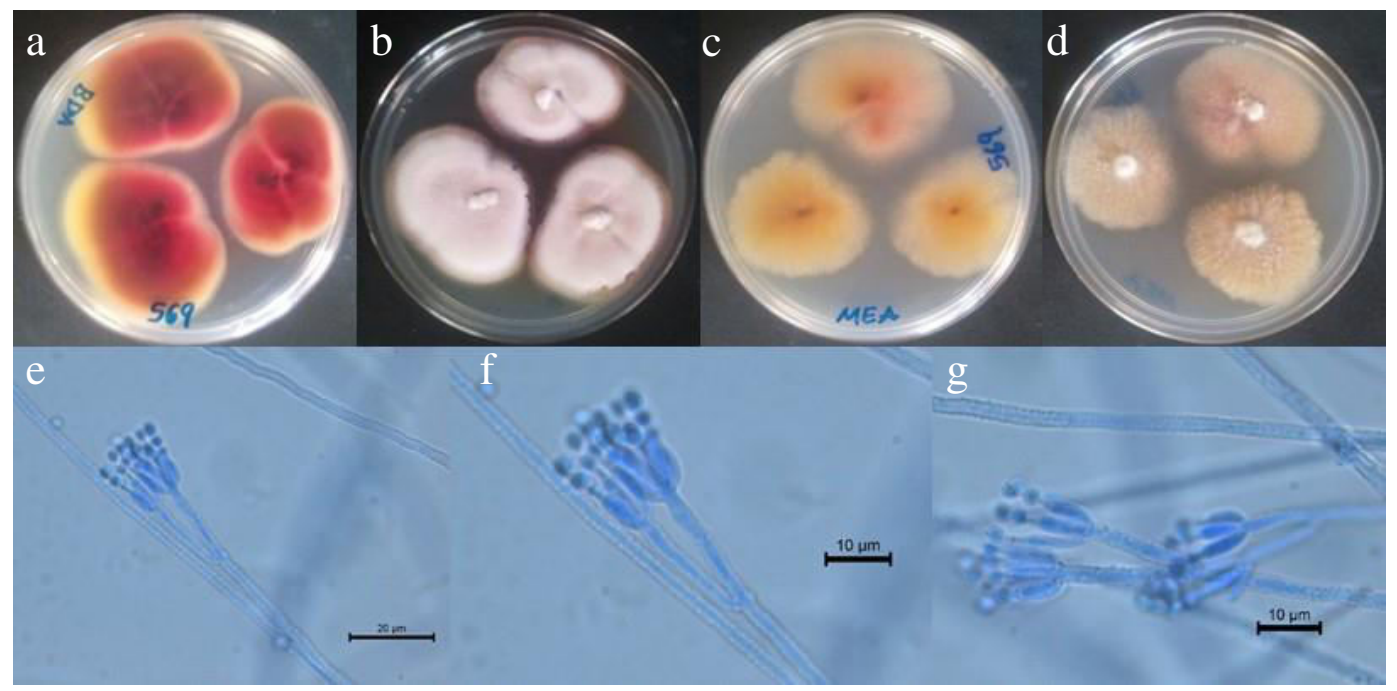

Figura 2. Macrocultivo e microcultivo do fungo Penicillium sp.: a) verso da colônia cultivada em meio ágar batata dextrose (BDA), b) frente da colônia cultivada em meio BDA, c) verso da colônia cultivada em meio ágar extrato de malte (MEA), d) frente da colônia cultivada em meio MEA, e), f) e g) conidióforos característicos do gênero Penicillium: estruturas de reprodução no formato de vassoura com ramificações 
A identificação por biologia molecular é uma forma mais moderna que consiste das seguintes etapas: i) extração do DNA, a partir do rompimento da parede celular e de membranas; remoção de impurezas e obtenção do DNA nuclear; ii) utilização da técnica de PCR, para amplificação da sequência de DNA. As sequências da região ITS são as mais utilizadas para a identificação dos fungos, sendo consideradas o segmento universal para este grupo; iii) visualização do segmento de DNA que foi amplificado usando eletroforese; iv) purificação do segmento de DNA, para eliminação dos reagentes utilizados na PCR; v) sequenciamento, que identifica a ordem dos nucleotídeos adenina, citosina, guanina e timina em um fragmento de DNA; vi) análises em programas computacionais, para encontrar similaridades entre as sequencias dos organismos alvos com sequências depositadas em um banco de dados. ${ }^{5,6}$ Um esquema deste processo é apresentado na Figura 3.

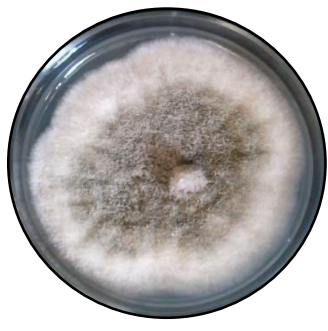

Fungo

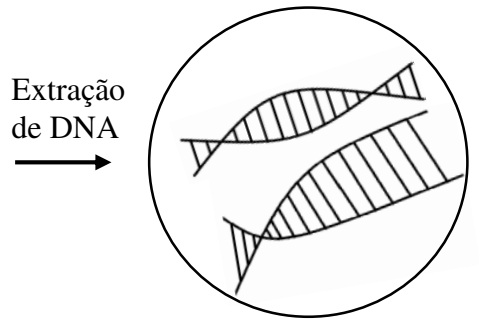

Fitas de DNA

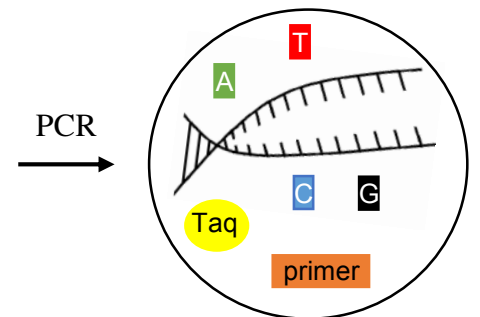

Componentes da PCR

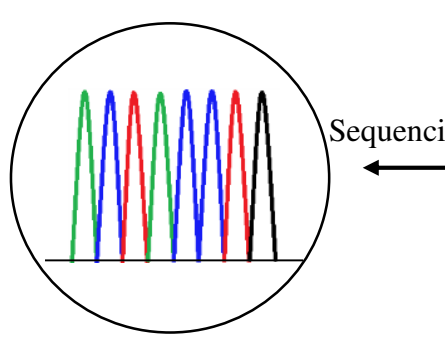

Eletroferograma

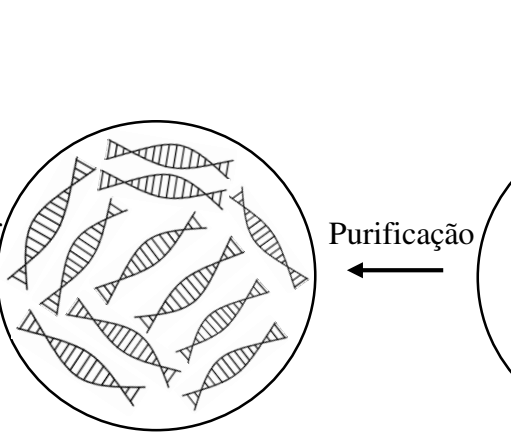

Retirada dos componentes da PCR

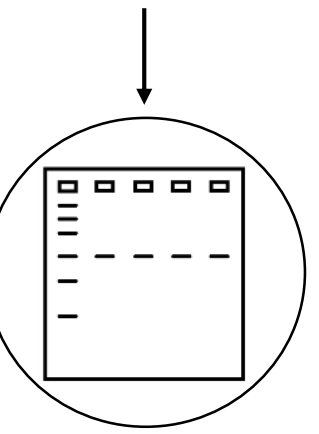

Eletroforese

Figura 3. Esquema das etapas utilizadas para a identificação molecular de fungos

Ressalta-se, também, a importância da utilização da taxonomia polifásica, que é a combinação de várias ferramentas de identificação como características morfológicas, fisiológicas, bioquímicas e moleculares para identificar e/ou descrever novas espécies de fungos. ${ }^{7}$ Porém, a química permitiu um grande avanço nesta área com a crescente utilização de espectrometria de massas, associada a técnicas estatísticas, para a identificação de fungos filamentosos e outros micro-organismos, patogênicos ou não. A identificação taxonômica (antes restrita a um número exíguo de especialistas) e a identificação molecular (que exige equipamentos específicos e insumos caros) ganharam na instrumentação química uma aliada, capaz de identificar micro-organismos a partir de quantidades pequenas de material biológico, em uma análise rápida e eficiente. A técnica de MALDI-TOF ampliou a agilidade de projetos de bioprospecção de metabólitos fúngicos, causando um impacto significativo também na medicina, pela possibilidade de identificar, com rapidez, micro-organismos patogênicos, inclusive em amostras biológicas recolhidas de pacientes, em substituição aos morosos processos convencionais de isolamento. ${ }^{8}$

Os fungos adquirem cada vez mais 
importantes funções em diversos setores importantes para o bem-estar e as atividades humanas, como na agricultura moderna. Antes, eram conhecidos nesta área principalmente por serem componentes da microbiota do solo, capazes de formar associações simbióticas com as plantas (fungos micorrízicos), gerando várias vantagens como biofertilização, bioregulação e proteção contra fungos fitopatogênicos. Na atualidade, espécies fúngicas têm sido cada vez mais utilizadas como bioinseticidas e bioherbicidas no controle biológico de pragas de forma inócua ao ambiente por serem capazes de produzir substâncias fungicidas, que podem ser utilizadas como alternativa para substituir pesticidas sintéticos, diminuindo a incidência da resistência de fungos fitopatôgenos e toxicidades potenciais para o ambiente e para os mamíferos. ${ }^{9} \mathrm{Na}$ medicina, destacam-se pela produção de medicamentos, como antibióticos (Penicillium chrysogenum) imunossupressores (Tolypocladium
inflatum), ${ }^{10}$ sendo que um vasto número de metabólitos bioativos tem sido descrito a cada ano, aumentando muito o potencial e o escopo de aplicação destas substâncias como fármacos. ${ }^{11} \mathrm{Na}$ indústria de alimentos, onde a atuação dos fungos é mais conhecida, estes são historicamente utilizados na produção de alimentos como pães (Saccharomyces cerevisiae), shoyo (Aspergillus oryzae), queijos (Penicillium roqueforti) e bebidas fermentadas, como cervejas, vinhos e cachaças (Saccharomyces cerevisiae), mas seu papel nesta área também tem aumentado, como será visto a seguir.

\section{Uso histórico e contemporâneo de fungos como alimentos}

A utilização dos fungos na alimentação, na forma de alimentos e bebidas fermentadas, é uma prática milenar. Pinturas rupestres criadas no Paleolítico retratavam eventos festivos, sugerindo que bebidas alcoólicas fermentadas já eram consumidas naquele tempo. $^{12}$ Estima-se que o processo fermentativo tenha surgido com a produção de queijos há mais de 8000 anos, na região entre o rio Tigre e Eufrates, que hoje pertence ao Iraque. Relatos indicam que, no Egito antigo, entre o período de $2000-4000$ a.C., surgiu a fermentação alcoólica com a produção de vinhos e cervejas, seguida da fabricação de pães. ${ }^{13}$

A fermentação, do ponto de vista bioquímico, é um processo metabólico de obtenção de energia a partir de compostos $\operatorname{orgânicos,~}^{14}$ sendo uma das técnicas mais antigas de conservação de alimentos e bebidas. Os micro-organismos mais usados são as bactérias e os fungos leveduriformes, embora fungos filamentosos tenham ocupado importantes nichos específicos nesta área. No entanto, foi apenas após o desenvolvimento do processo de pasteurização que os micro-organismos passaram a ser reconhecidos como os responsáveis pela fermentação, produzindo uma grande variedade de compostos antimicrobianos e substâncias proteicas que podem inibir ou reduzir a carga de microorganismos indesejáveis no alimento. ${ }^{13}$ Atualmente, o consumo de produtos fermentados vem aumentando, principalmente por suas propriedades probióticas, aumentando o número de estudos sobre micro-organismos úteis em processos fermentativos.

A fermentação desempenha algumas funções no processamento de alimentos (Figura 4), como o desenvolvimento de grande variedade de sabores, aromas e texturas; a conservação do alimento pela formação de metabólitos inibidores como ácidos orgânicos (láctico, acético, fórmico e propiônico), álcoois (etanol), bactericinas; além da combinação da produção desses metabólitos com a diminuição da atividade de água (pela secagem ou adição de sal); a promoção de maior segurança alimentar pela inibição de patógenos ou redução de compostos tóxicos; o enriquecimento do alimento pela produção de vitaminas, proteínas, aminoácidos e ácidos graxos 
essenciais, aumentando o valor nutricional dos alimentos e das bebidas. ${ }^{14,15}$

As leveduras podem ser utilizadas sozinhas ou em conjunto com fungos filamentosos ou bactérias (geralmente bactérias ácido lácticas) em processo fermentativos. Cerca de 21 gêneros de leveduras são utilizados para produção de alimentos e bebidas fermentados:
Brettanomyces, Candida, Cryptococcus, Debaryomyces, Galactomyces, Geotrichum, Hansenula, Hanseniaspora, Hyphopichia, Kluyveromyces, Metschnikowia, Pichia, Rhodotorula, Saccharomyces, Saccharomycodes, Saccharomycopsis, Schizosaccharomyces, Torulopsis, Trichosporon, Yarrowia, e Zygosaccharomyces. ${ }^{14,16}$

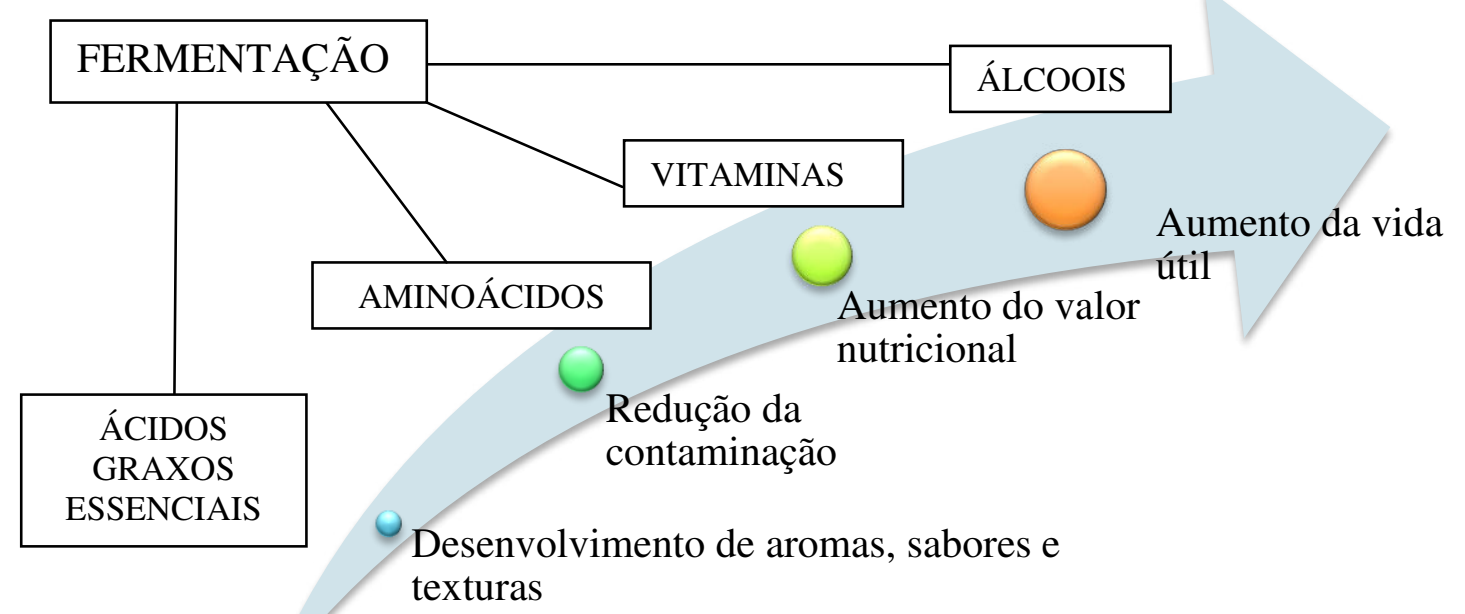

Figura 4. O papel da fermentação na conservação de alimentos

Os fungos filamentosos mais comuns usados em processos fermentativos são Actinomucor, Amylomyces, Aspergillus, Monascus, Mucor, Neurospora, Penicillium, Rhizopus. São muito utilizados na Ásia para fabricação de alimentos e bebidas fermentados, como furu, fermentado de soja rico em sabor, e o ildi, um pequeno bolo esponjoso obtido do cozimento de arroz parboilizado feijão-da-índia (Phaseolus mungo). Na Europa, são usados na produção de queijos, produtos cárneos e salsichas. Os fungos conferem propriedades funcionais aos alimentos fermentados uma vez que produzem enzimas (maltases, invertases, pectinases, alfa-amilases, betagalactosidases, amiloglucosidases, celulases, hemicelulose, proteases, lipases) e também promovem a degradação de fatores antinutricionais, melhorando assim a biodisponibilidade de minerais. ${ }^{16,17}$

Nos processos fermentativos, leveduras foram historicamente mais utilizadas, destacando-se dentre elas Saccharomyces cerevisiae, uma vez que é a responsável pela tão conhecida fermentação alcoólica, hidrolisando açúcar (glicose), para obtenção do etanol. Cervejas, vinhos e pães são obtidos através da fermentação alcoólica (Figura 5). No entanto, outras leveduras têm papeis importantes na elaboração de alimentos fermentados, como Yarrowia lipolytica que desempenha um papel na fermentação de açúcar, possui enzimas proteolíticas e de urease lipolíticas e reduz o ranço de gordura no produto. ${ }^{18}$ 


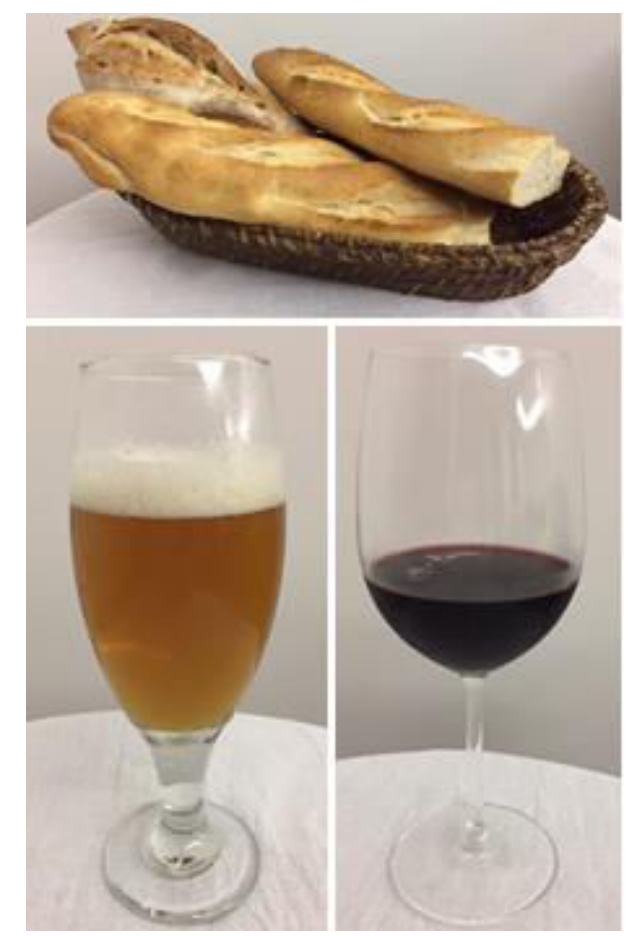

Figura 5. Alguns alimentos obtidos por fermentação alcoólica

Além de pães, cervejas e vinhos, diversos outros alimentos são produzidos por leveduras em processos fermentativos, sendo pouco conhecidos por não serem itens da alimentação ocidental usual. Um exemplo é o kefir, bebida láctea que apresenta baixo teor alcoólico, muito popular no Oriente Médio, que difere de outros leites fermentados, porque se utiliza uma cultura na forma de grãos para iniciar o processo fermentativo. Esses grãos possuem uma estrutura específica, coloração branca amarelada e são compostos por um conjunto de microorganismos (bactérias ácido lácticas, bactérias ácido-acéticas e leveduras) que atuam em uma relação simbiótica para formação do sabor e aroma do kefir. As espécies presentes nos grãos são Kluyveromyces marxianus, Torulaspora delbrueckii, S. cerevisiae, Candida kefir, Saccharomyces unisporus, Pichia fermentans e Y. lipolytica. ${ }^{19}$

Outro alimento produzido por fermentação é o polvilho azedo, produto típico brasileiro obtido da fermentação da mandioca por bactérias ácido-lácticas, em especial Lactobacillus. No entanto, leveduras como Geotrichum, Saccharomyces, Brettanomyces, Pichia spp. e Galactomyces geotrichum também têm papel importante no processo, pois além de atuarem no amolecimento da mandioca para facilitar o processo, contribuem para melhoria das características sensoriais do produto final e promovem o enriquecimento nutricional do produto fermentado. ${ }^{20,21}$

Já o uso de fungos filamentosos na produção de alimentos pode ser detacado na produção de queijos. Associados a leveduras (Trichosporon spp., Y. lipolytica, $K$. lactis e Candida spp.), fungos filamentosos (Penicillium spp.) são responsáveis pelo desenvolvimento de sabores e aromas característicos de determinados queijos ${ }^{22}$ como o Camembert, um queijo produzido por leite de vaca não pasteurizado. Em uma das etapas do processo, borrifa-se um aerossol contendo Penicillium camembertii e $P$. candidum, que formam uma camada branca na superfície do queijo durante o período de maturação, produzindo enzimas lipolíticas e proteolíticas que promovem amaciamento e desenvolvimento do sabor e aroma característicos. $^{22,23}$ Já o queijo Roquefort, 
feito a partir de leite de ovelha, tem coloração verde azulada devido à ação do Penincillium roqueforti, que produz lipases hidrossolúveis, responsáveis pela formação de ácidos caproico, caprílico e cáprico, que conferem características sensoriais específicas. $^{23}$

Os fungos, leveduras e bactérias ácidolácticas contribuem também para o desenvolvimento das características sensoriais de produtos cárneos fermentados e salsichas. Entre os fungos filamentosos, os do gênero Penicillium são usados nas culturas iniciadoras, muito embora espécies de outros gêneros, como Aspergillus e Eurotium também contribuam para a fermentação e maturação de carnes. Os fungos filamentos participam do desenvolvimento do sabor e aroma desses produtos produzindo enzimas extracelulares (amilases, lipases e proteases) que hidrolisam carboidratos, gorduras e proteínas, respectivamente, em substâncias voláteis. $^{22}$

Os fungos mais usados no processo de maturação de produtos cárneos fermentados são Penicillium nalgiovense, $P$. chrysogenum, $P$. camembertii. Outros fungos como $P$. commune, $P$. aurantiogriseum, $P$. olsonii, $P$. nalgiovensee e $P$. chrysogenum são fundamentais no processo de fabricação do salame. As leveduras também ajudam no desenvolvimento do sabor desses produtos por produzirem enzimas lipolíticas e proteolíticas. Sendo Debaryomyces polymorphus, $\quad$ C. zeylanoides, $P$. membranifaciens, $P$. guilliermondii, e Cryptococcus spp. as responsáveis pelo processo de maturação do presunto curado. $^{22}$

A fermentação dos grãos de soja por fungos filamentosos (Rhizopus e Aspergillus) é uma prática milenar em muitos países asiáticos. Cada país possui um fermentado de soja típico, como o tempe na Indonésia, douchi e sufu na China e miso e shoyu no Japão. $^{16}$ O tempe, muito popular na Indonésia, é rico em nutrientes, proteínas, fibras e substâncias ativas. O fungo Rhizopus oligosporus é o principal responsável por esta fermentação, sendo essencial para a produção do tempe, embora a cultura iniciadora seja composta por outros fungos filamentosos, além de leveduras e bactérias. ${ }^{17,24}$ Fungos como $R$. oryzae e Mucor spp. também contribuem para a formação da textura, aroma e o valor nutricional do produto final. $^{24}$

As culturas microbianas utilizadas na produção de alimentos fermentados usualmente fazem parte da composição dos mesmos. Como um número significativo de pessoas tem consumido esses alimentos durante muitos séculos, estes microorganismos são classificados como Gennerally Recognized as Safe (GRAS). No entanto, a determinação de segurança GRAS é sempre limitada às condições de uso, ${ }^{14}$ de forma que um fungo considerado GRAS para um tipo de alimento, não é necessariamente GRAS para outro.

O número de espécies fúngicas reconhecidamente benéficas na produção de alimentos aumentou significativamente. Dentre os eucariotas pode-se citar: Aspergillus, Cyberlindnera, Cystofilobasidium, Dekkera, Guehomyces, Hanseniaspora, Kazachstania, Lachancea, Lecanicillium, Metschnikowia, Mucor, Neurospora, Rhizopus, Schizosaccharomyces, Schwanniomyces, Scopulariopsis, Sporendonema, Starmerella, Torulaspora, Trigonopsis, Wickerhamomyces, Yarrowia, Zygosaccharomyces e Zygotorulaspora. Considerando ainda a soja e outros vegetais fermentados, podem-se incluir leveduras e fungos filamentosos: Aspergillus, Guehomyces, Mucor, Neurospora, Rhizopus e Zygosaccharomyces. ${ }^{14}$

Com a conscientização da população dos benefícios de uma alimentação mais saudável, a indústria de alimentos começou a se movimentar para desenvolver novos produtos atendendo a esse novo nicho de mercado. Ácidos orgânicos, antioxidantes e pigmentos têm sido cada vez mais produzidos por processos fermentativos para atender a demanda industrial. Fungos filamentosos são uma potencial fonte de pigmentos naturais e uma alternativa às fontes atualmente utilizadas, despertando o interesse de vários 
segmentos. A utilização de fungos para a produção de pigmentos torna a indústria independente do fornecimento sazonal de matérias-primas vegetais e a obtenção de um insumo mais padronizado. ${ }^{25}$ Alguns pigmentos produzidos por fungos com qualidade alimentar estão presentes no mercado, como os pigmentos de Monascus, o Natural $\operatorname{Red}^{\mathrm{TM}}$, produzido por Penicillium oxalicum, a riboflavina produzida por Ashbya gossypii, o licopeno e o $\beta$-caroteno, produzidos por Blakeslea trispora. ${ }^{26}$ Os pigmentos de Monascus são policetídeos de coloração vermelha e amarela produzidos pelo fungo Monascus sp.. Sua utilização ainda não é aprovada nem pela União Europeia, nem pelos Estados Unidos, devido à possibilidade de contaminação por micotoxinas, mas são legalmente produzidos e comercializados como corantes alimentares no sudeste asiático. ${ }^{27}$

\subsection{Cogumelos}

No período paleolítico, os cogumelos já eram conhecidos pelas propriedades alucinógenas sendo cultivados na China desde 600 a.C. onde são consumidos tradicionalmente como alimentos. ${ }^{28}$

Dentre as espécies conhecidas de fungos, 12 mil são classificadas como cogumelos, sendo que, destas, duas mil são descritas como comestíveis. Alguns dos cogumelos mais cultivados no mundo são o Agaricus biporus (champignon), Lentinus edobes (shiitake), Pleorotus spp. (shimeji), Auricularia auricula (cogumelo orelha de pau) e Vouvariella volvacea (cogumelo palha).

Atualmente, o consumo de cogumelos vem se difundindo melhor no mundo inteiro, devido ao seu sabor refinado e às propriedades medicinais e funcionais. Estudos sobre a composição química destes fungos apontam que possuem vários compostos biologicamente ativos, como polissacarídeos e glicoproteínas, que thes conferem propriedades antioxidante, anti- inflamatória antitumoral e imunomodulatória. Além disso, são fontes de prebióticos, pois contêm carboidratos complexos (quitina, hemicelulose, alfa e beta glucanas, mananas, galactanas e xilanas). A quitina, por exemplo, é um polissacarídeo insolúvel em água e, por não ser hidrolisada por enzimas do organismo humano, confere característica prebiótica aos cogumelos. ${ }^{29,30}$

No Brasil, os estudos químicos sobre cogumelos cultivados têm crescido muito, com conseqüente aumento na produção, comercialização e consumo dos mesmos, sendo A. bisporus, L. edobes e Pleorotus spp. as espécies mais produzidas e consumidas. Esses cogumelos constituem excelente fonte de proteínas e alto teor de fibras alimentares, além de possuírem baixo teor de lipídeos. ${ }^{30,31}$ São considerados nutracêuticos, pois apresentam várias moléculas bioativas, como os polissacarídeos $\beta$-glucanas, triterpenos e antioxidantes.

O cogumelo do sol (Agaricus Blazei Murill) é nativo do Brasil e vem sendo cultivado desde o início da década de 90 . O aumento do interesse e consequente consumo desse cogumelo deve-se às propriedades antitumoral, anticarcinogênica, antiviral, antiinflamatória, hipoglicêmica, antihipertensiva, hipoglicêmico e hipocolesterolêmica. ${ }^{32}$

Hoje em dia, os "cogumelos nutracêuticos" são produzidos como extratos refinados, biomassa seca do micélio ou mesmo como corpos de frutificação do fungo, que são consumidos sob a forma de cápsulas, comprimidos e pós, comercializados como suplementos dietéticos com propriedades terapêuticas. Esse consumo ainda se concentra na Ásia, onde há diversas empresas que comercializam o produto, ${ }^{33}$ embora o mundo ocidental venha cada vez mais aderindo ao consumo destes nutracêuticos. A crescente demanda mundial por produtos nutracêuticos tornou esse, um mercado multibilionário. ${ }^{34,35}$ 


\section{Fungos e a produção de metabólitos secundários bioativos}

Os metabólitos secundários são produtos naturais que geralmente apresentam baixa massa molecular, estrutura química complexa e alto potencial farmacológico. Podem ser produzidos como mecanismo de defesa contra predadores, podendo estar envolvidos no processo reprodutivo de algumas espécies, ou serem produzidos para desenvolver funções biológicas específicas da espécie que o produz. ${ }^{36}$ Esses metabólitos são essenciais para a regulação, equilíbrio e sobrevivência fúngica. ${ }^{37}$

Um marco na história dos fungos quanto à produção de metabólitos secundários bioativos foi a descoberta da penicilina (1) em 1929 por Alexander Fleming a partir da espécie Penicillium crysogenum. ${ }^{38}$ Esse importante antibiótico revolucionou o século $X X$, sendo determinante para salvar inúmeras vidas, inclusive durante a Segunda Guerra Mundial. Além disso, tomando sua estrutura química como modelo, a indústria farmacêutica desenvolveu novos antibióticos de extrema importância, como ampicilina (2), amoxilina (3) e meticilina (4)..$^{39}$ Outro notável metabólico secundário fúngico, a ciclosporina A (5), produzido pela espécie Tolypocladium inflatum, foi o primeiro imunossupressor a ser descoberto, o qual teve importância fundamental na medicina viabilizando transplantes, ao atuarem na redução da probabilidade de rejeição de órgãos nos pacientes transplantados. ${ }^{40}$ Outros fármacos obtidos a partir de fungos e que têm uma grande relevância terapêutica são a lovastatina (6) e mevastatina (7), que atuam como redutores de colesterol e foram isolados de Aspergillus terreus e Penicillium spp., respectivamente. ${ }^{39}$<smiles>CC(=O)N[C@H]1C(=O)N2[C@@H](C(=O)O)C(C)(C)S[C@H]12</smiles>

1<smiles>[R]c1ccc([C@H](N)C(=O)N[C@H]2C(=O)N3[C@@H](C(=O)O)C(C)(C)S[C@H]23)cc1</smiles>

$2 \mathrm{R}=\mathrm{H}$

$3 \mathrm{R}=\mathrm{OH}$<smiles>COc1cccc(OC)c1C(=O)N[C@H]1C(=O)N2[C@@H]1SC(C)(C)[C@H]2C(=O)O</smiles>

4

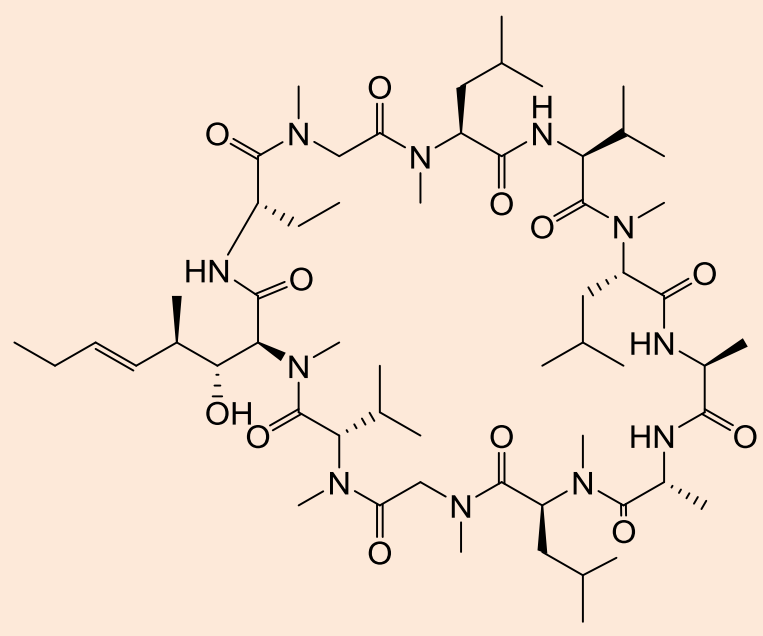

5<smiles>[R][R5]=C</smiles>

$7 \mathrm{R}=\mathrm{H}$

Figura 6. Estrutura química do antibiótico penicilina (1) e de seus derivados 2, 3 e 4; do imunossupressor ciclosporina A (5); e dos hipercolesterolêmicos lovastatina (6) e mevastatina 
Além disso, há relatos de inúmeras substâncias obtidas a partir de fungos que aparesentam as mais variadas atividades biológicas, como os antitumorais aspergiolídio (8), obtido da espécie
Gliocladium roseum e o alcaloide (9), isolado do fungo Chaetomium sp. Já a ganodermicina (10) é uma substância isolada da espécie Ganoderma licidum e apresenta atividade anti-inflamatória (Figura 7). ${ }^{41}$<smiles></smiles>

8<smiles>CC1C(=O)N2c3ccccc3[C@@]3(O)C[C@H](n4cnc5ccccc5c4=O)C(=O)N1C23</smiles>

9<smiles>CC1(C)OC1C(=O)C=CC1CCC(C(=O)O)CC1</smiles>

10

Figura 7. Metabólitos secundários aspergiolídio (8), chaetominina (9) e ganodermicina (10) obtidos a partir de fungos

Para a produção de metabólitos fúngicos bioativos, diversos parâmetros de cultivo como composição do meio de cultivo, temperatura, aeração e tempo de crescimento podem ser alterados. ${ }^{42}$ Estas alterações podem levar a uma diversificação metabólica, abordagem denominada como OSMAC (One Strain, Many Compounds). ${ }^{43}$

Partindo desta prerrogativa, Wang e colaboradores (2014) cultivaram a espécie Ascotricha sp. em condições distintas, utilizando um meio eutrófico (rico em nutrientes) e em outro oligotrófico (pobre em nutrientes) e, também, avaliaram a interferência da concentração de íons $\mathrm{Mg}^{2+}$ nos caldos de cultivo no metabolismo secundário do fungo. ${ }^{44}$ Esta espécie é conhecida por produzir ciclonerolidol e dicetopiperazinas quando cultivada em meios de cultura ricos em nutrientes. ${ }^{45}$ Como resultados desse estudo, foram isolados três derivados cariofilênicos até então nunca relatados para a espécie; (+)-6-Odemetilpestalotiopsina A (11) e (+)-6-Odemetilpestalotiopsina $C(\mathbf{1 2})$, isolados ao se cultivar o fungo no meio oligotrófico e na ausência de íons $\mathrm{Mg}^{2+}$, enquanto que o (-)-6O-demetilpestalotiopsina B (13) foi obtido a partir do cultivo do fungo no meio oligotrófico suplementado com íons $\mathrm{Mg}^{2+}$. Esses novos metabólitos obtidos (Figura 8) apresentaram atividade contra células leucêmicas, o que comprova que pequenas alterações realizadas no meio de cultivo podem levar à obtenção de novos compostos com pronunciada atividade biológica. 


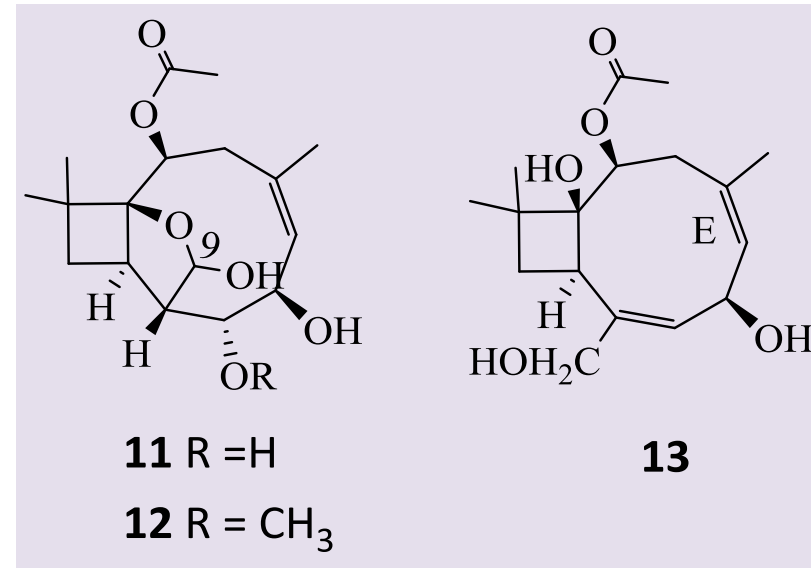

Figura 8. Derivados cariofilênicos inéditos obtidos do fungo Ascotricha sp. cultivado em diferentes condições

Porém, apesar de serem conhecidos inúmeros metabólitos fúngicos, o avanço das técnicas moleculares, que permitiu o mapeamento genético de fungos mostrou que os genes responsáveis pela biossíntese de uma rota particular de metabólitos secundários estão ordenados em grupos fisicamente relacionados denominados clusters que, em sua maioria, encontram-se silenciados em condições normais de cultivo. ${ }^{46}$ Sendo assim, percebeu-se que as espécies fúngicas ainda não foram eficazmente exploradas quanto à sua capacidade de biossintetizar novos metabólitos, tendo em vista que as condições de cultivo adotadas em laboratórios nem sempre permitem a expressão desses metabólitos crípticos. ${ }^{47}$ Nos últimos anos, muitas técnicas têm sido aplicadas visando maximizar e/ou potencializar quantitativamente a produção de metabólitos secundários, ${ }^{48}$ pelo entendimento de que podem-se ativar rotas biossintéticas até então silenciadas, levando à expressão de novas substâncias pelo fungo.

Uma maneira de obter diversificação metabólica a partir de fungos é através da incorporação de agentes epigenéticos aos meios de cultivo. Esses agentes são capazes de ativar rotas biossintéticas silenciadas ou provocar o silenciamento de genes responsáveis pela produção de determinados metabólitos, sem provocar modificação no material genético. ${ }^{49}$ Esta diversidade estrutural (Figura 9), refletida no isolamento de compostos das mais diversas classes químicas, está quase sempre atrelada a uma miríade de atividades biológicas. Dentre as classes de compostos obtidos a partir de fungos destacam-se os alcaloides paecilomida, obtido do fungo Paecilomyces lilacinus $^{50}$ e epoxiisoequinulina $A$, isolado de Aspergillus ruber; ${ }^{51}$ terpenos como o ácido betulínico, importante triterpeno isolado da espécie Phomopsis sp. $;^{52}$ antraquinonas como a 1,2,8-trihidroxiantraquinona isolada da espécie endofítica Nigospora sp.; ${ }^{53}$ policetídeos como o selesconol, isolado a partir de Daldinia eschscholzii ${ }^{54}$ e três novas wortmannilactonas, isoladas a partir da espécie Talaromyces wortmannii; ${ }^{55}$ flavonoides como a miricetina, isolada do fungo Xylaria papulis ${ }^{56}$ e três quercetinas monoglicosiladas, isoladas pela primeira vez de fungos, obtidas a partir de Nigrospora oryzae $;^{57}$ a penicillantona, uma nova xantona obtida de Penicillium aculeatum; ${ }^{58}$ cumarinas como as furoisocumarinas

Asperisocumarinas $A$ e $B$ e as isocumarinas Asperisocumarinas $E$ e $F$, isoladas de Aspergillus sp., ${ }^{59}$ entre outras. 


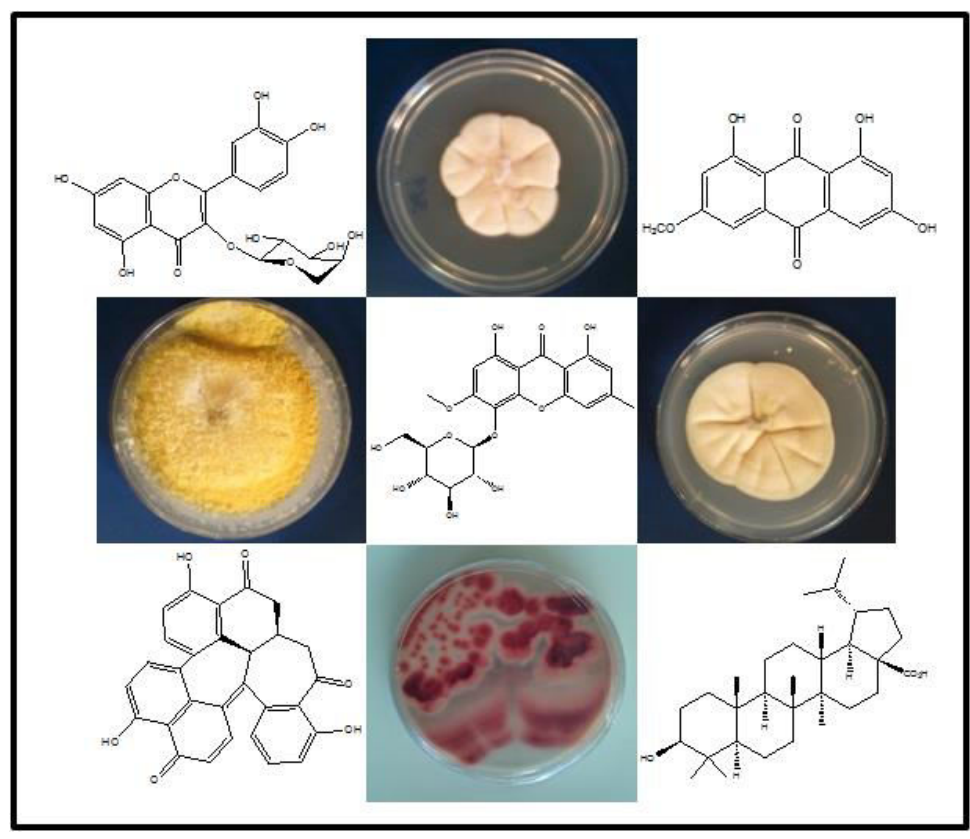

Figura 9. Ilustração da diversidade química de metabólitos fúngicos

A regulação epigenética pode ser realizada através de três mecanismos principais de regulação gênica: metilação do DNA, modificação de histonas e silenciamento pós-transcripcional por pequenos microRNAs não codificados. Dentre os citados, os dois primeiros são utilizados para ativar rotas silenciadas de produção metabólica. Esse processo se dá através da utilização de moléculas que atuam na metilação da citosina no DNA ou alterando as histonas, por meio de acetilação, fosforilação, metilação, entre outros, que promovem a alteração estrutural na cromatina, levando assim, à expressão e/ou silenciamento de determinadas rotas biossintéticas. $^{47,60}$

Utilizando essa abordagem, Du e colaboradores (2014) cultivaram a espécie Daldinia sp na presença de ácido hidroxâmico suberoilanilida (SAHA), um inibidor de histona desacetilase. ${ }^{61}$ Esse estudo possibilitou a obtenção de dois policetídeos, a daldinona B (14) e daldinona E (15), este último relatado pela primeira vez para essa espécie (Figura 10). Ambos compostos foram ativos contra Staphylococcus aureus e Klebsiella pneuminiae, bactérias resistentes à meticilina e apresentaram atividade antioxidante.<smiles>O=C1c2c(cc(O)c3c2C2=CC=C(O)c4c(O)ccc2c4-3)[C@H](O)[C@H]1O</smiles>

14<smiles>O=C1c2c(cc(O)c3c2C2=CC=C(O)c4c(O)ccc2c4-3)[C@H](O)[C@@H]1O</smiles>

15

Figura 10. Policetídeos 14 e $\mathbf{1 5}$ obtidos a partir de Daldinia sp. cultivado na presença de SAHA 
Em termos concretos, estima-se que entre os anos de 2004 e 2014 tenham sido introduzidas cerca de 360 novas drogas em estudos clínicos, oriundas de fontes naturais, inclusive fungos, para o tratamento de distintas doenças, como anti-Alzheimer, antiartríticos, anticancer, antidiabéticos, entre outras. ${ }^{11}$ Muitos resultados positivos tem sido obtidos, como é o caso do Fingolimode (Gylenia $^{\mathrm{TM}}$, Novartys), um análogo sintético do metabólito fúngico miriocina, ${ }^{62}$ introduzido no mercado farmacêutico em 2010 para tratamento de esclerose múltipla. A miriocina foi isolada da espécie Isaria sinclairii, estágio imperfeito de Cordyceps sinensis Sacc. Essa espécie fúngica, pertencente à família Clavicipitaceae e ao gênero Cordyceps, é parasítica de insetos e amplamente utilizada na medicina tradicional chinesa. ${ }^{63}$ Os estudos iniciais com o Fingolimode foram voltados para a sua aplicação como imunossupressor em transplante renal, na tentativa de substituir a ciclosporina. Porém não houve avanços nesse âmbito, visto que o Fingolimode apresentouse menos eficaz do que a ciclosporina, mas, ao serem introduzidos novos ensaios, administrando-se esse fármaco no tratamento de esclerose múltipla, foram obtidos resultados promissores contra a doença já nos testes iniciais. ${ }^{64} \mathrm{~A}$ esclerose múltipla é uma doença crônica autoimune causadora de desordens cerebrais e danos à mielina, o que acarreta em interferências entre o cérebro e o sistema nervoso central. ${ }^{65}$ São inúmeros os sintomas relacionados a esta doença, como, por exemplo, tremores, alterações nos rins e bexiga, espasmos, alterações cognitivas, problemas visuais, fraqueza muscular, entre outros. Estima-se que haja cerca de 2,5 milhões de pessoas acometidas em todo o mundo, sendo diagnosticados cerca de 200 novos casos por semana somente nos Estados Unidos da América. Essa doença geralmente é diagnosticada entre 20 e 40 anos, com predominância em mulheres. $O$ custo estimado por paciente por ano nos EUA é de U\$ 8,528 - U\$ 54,244. Sendo assim, novos medicamentos para o tratamento desta doença é urgente, a fim de amenizar seus sintomas e diminuir os custos relacionados ao tratamento. ${ }^{66}$

A expansão da busca por espécies fúngicas a partir de novas fontes também tem sido um importante aliado para a descoberta de novos metabólitos fúngicos bioativos, já que fungos podem ser encontrados em ambientes inabitáveis pela maioria dos organismos vivos, com temperaturas $^{67}$ e $\mathrm{pH}^{68}$ extremos, altas pressões barométricas, ${ }^{69}$ alta salinidade ${ }^{70} \mathrm{em}$ fendas hidrotermais, ${ }^{71}$ desertos ${ }^{72}$ e em gelos do Ártico ${ }^{73}$ e da Antártica. ${ }^{74} \mathrm{~A}$ adaptação metabólica de espécies fúngicas a esses habitats pode levar ao desenvolvimento de rotas biossintéticas especializadas, raras e propocionar a produção de metabólitos com estruturas únicas e atividade biológicas diferenciadas, sendo outra grande esperança da pesquisa moderna em química de fungos.

\section{Isolamento e caracterização de metabólitos secundários bioativos}

A produção de metabólitos secundários ocorre geralmente no final do processo fermentativo, quando o fungo atinge a fase estacionária. ${ }^{75}$ Desta forma, experimentos visando o isolamento destas substâncias são geralmente longos, com duração a partir de sete dias, sendo, porém, mais comum as fermentações com três a quatro semanas de duração. A obtenção de extratos é normalmente feita utilizando-se solventes de média polaridade, como o acetato de etila e o método cromatográfico mais empregado para o isolamento de substâncias é a cromatografia líquida, podendo ser feita por adsorção, exclusão ou filtração molecular e troca iônica. O processo de separação por troca iônica baseia-se na troca de íons entre a fase móvel e resinas que podem ser catiônicas ou aniônicas (fase estacionária e é utilizado para separar substâncias que contenham grupamentos ionizáveis, como alcaloides, aminoácidos, proteínas e outras biomacromoléculas. Já no processo por exclusão, a fase estacionária é composta por 
um gel poroso e a separação baseia-se no tamanho das partículas do soluto que irão atravessar a fase estacionária.

A utilização de cromatografia líquida de alta eficiência (CLAE) acoplada a diversas técnicas de identificação estrutural confere agilidade ao processo. A associação mais tradicionalmente utilizada é o acoplamento de cromatografia líquida de alta resolução à espectroscopia de ultravioleta-vísivel, HPLC/UV, ${ }^{44}$ podendo ser modernizada pelo acoplamento de detector por espectrometria de massas, LC/UV/MS. ${ }^{76}$ Outras técnicas hifenadas são também utilizadas nesta área, tais como LC/MS/NMR, ${ }^{77}$ LC/ELSD $^{78}$ e UHPLC/DAD/QTOF. ${ }^{79}$

A abordagem metabolômica tem se mostrado promissora para fornecer o perfil metabólico de uma determinada espécie fúngica, cultivada em condições específicas. Igualmente de sucesso, o HTS (High Througput Screening) utiliza processos automatizados para o processamento de um elevado número de dados para mapeamento rápido e eficiente dirigido à prospecção de novas substâncias biologicamente ativas o que reduz o tempo de descoberta de substâncias de interesse econômico. O primeiro fármaco comercial obtido a partir de análises HTS foi o antitumoral Nexavar ${ }^{\circledR}$ (tosilato de sorafenibe). Em 2014, a indústria farmacêutica alemã lançou no mercado a segunda droga obtida utilizando esse enfoque, Translarna ${ }^{\circledR}$ (atalureno), a qual é utilizada no tratamento de pacientes com distrofia muscular de Duchenne. ${ }^{11,78}$

\section{Aplicação de fungos para a biotransformação de produtos naturais e fármacos}

realizadas por fungos são uma alternativa biotecnológica para a obtenção de novos compostos ativos, em especial quando as modificações estruturais desejadas não podem ser efetuadas utilizando-se métodos sintéticos clássicos.

O uso de reações químicas utilizando micro-organismos ocorre há mais de seis mil anos, desde o início da conversão do açúcar em álcool para produção de cervejas e vinhos, mas considera-se que o primeiro relato científico de biotransformação seja datado do final do século XIX, quando Louis Pasteur resolveu uma mistura racêmica de ácido tartárico utilizando Penicillium glaucum. O micro-organismo adicionado à mistura racêmica degradou somente um enantiômero, deixando o outro intacto. ${ }^{82}$

Durante o início do século $X X$, os processos de biotransformações mais estudados referiam-se à conversão de $D$ Glucose em L-Sorbose na síntese do ácido ascórbico (vitamina C). ${ }^{82}$ A utilização efetiva de micro-organismos em reações orgânicas foi relativamente lenta até a década de 1950, quando conversões seletivas com fungos passaram a ser estudadas e empregadas na indústria, cujo marco foi a hidroxilação da progesterona pelo fungo Rhizopus arrhizus na síntese da cortisona. Essa biotransformação reduziu a síntese da cortisona de 31 para 11 etapas e diminuiu os custos de produção em $200 \% .^{83,84}$

A biotransformação de produtos naturais e fármacos pode ser realizada tanto com enzimas isoladas quanto com organismos vivos. Na academia, a maior parte das pesquisas utiliza fungos para realizar biotransformações, usualmente utilizando produtos naturais isolados de plantas como material de partida. A utilização de fungos em reações de biotransformação, em detrimento do uso de enzimas isoladas, pode ser vantajosa pelo menor custo da manipulação de fungos frente ao custo do isolamento de enzimas, pela facilidade operacional e pela possibilidade de reintegração celular, ou seja, uma única cepa fúngica pode ser usada durante anos em 
diversas biotransformações. ${ }^{85}$ Além disso, trata-se de uma metodologia verde, devido ao uso reduzido de solventes e reagentes, bem como na menor produção de resíduos nocivos para a saúde e para o ambiente.

As reações de biotransformação podem ser classificadas em dois grupos: biotransformação de xenobióticos e biotransformação biossinteticamente dirigida. ${ }^{86} \mathrm{Na}$ biotransformação de xenobióticos, o substrato a ser biotransformado deve ser estranho ao metabolismo secundário do fungo utilizado, enquanto que, em biotransformação biossinteticamente dirigida, o substrato a ser biotransformado deve ser análogo a algum intermediário biossintético natural produzido pelo fungo. ${ }^{86} \mathrm{Um}$ bom exemplo de biotransformação biossinteticamente dirigida pode ser visualizado na Figura 11, referente à biotransformação do diterpeno caurânico ácido $7 \beta$-hidroxicaurenoico (16) pelo fungo Giberella fujikuroi. G. fujikuroi é uma espécie conhecida por produzir giberelinas, importantes hormônios de crescimento vegetal, a partir de ácido caurenoico, um precursor diterpênico com esqueleto caurânico. ${ }^{87}$ Quando admistrado a uma cultura de G. fujikuroi, o fungo biotransformou o diterpeno caurânico $16 \mathrm{da}$ mesma forma que metabolizaria o precursor biossintético natural das giberelinas, produzindo contração do anel e levando ao isolamento de um produto rearranjado com esqueleto de giberelinas.

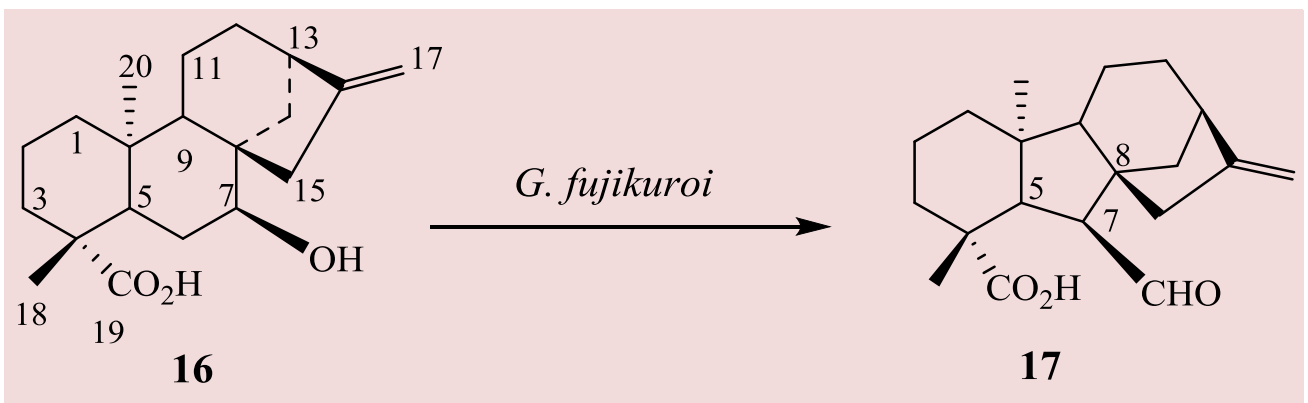

Figura 11. Biotransformação biossinteticamente dirigida realizada com o fungo G. fujikuroi

Porém, para que as biotransformações biossinteticamente dirigidas possam ocorrer, a substância administrada ao fungo precisa atender a requerimentos estruturais adequados à formação do complexo enzimasubstrato. Desta forma, no caso de $G$. fujikuroi, por exemplo, não é suficiente que o substrato seja da classe dos diterpenos caurânicos. Por exemplo, a biotransformação do diterpeno caurânico acetato de candol A $(\mathbf{1 7})^{88}$ levou à obtenção de seis produtos, nos quais ocorreu a oxidação do grupo metílico C19 em álcool (18), aldeido (19) e ácido carboxílico (20), bem como a hidroxilação do derivado contendo o ácido carboxílico em C19 nas posições 3 (21), 2 e 3 (22) e 3 e 18 (23) (Figura 12). Entretanto, derivados rearranjados com esqueleto gibânico (biotransformação biossinteticamente dirigida) não foram obtidos. 
<smiles>C=C1C[C@]23CC1CCC2[C@@H]1CCCC(C)(C)C1C[C@H]3OC(C)=O</smiles>

19

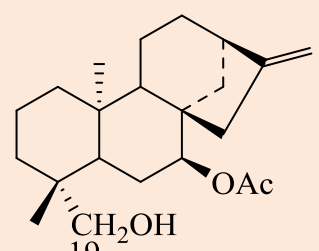

18

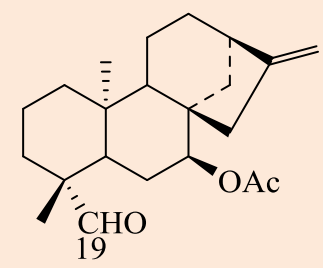

19

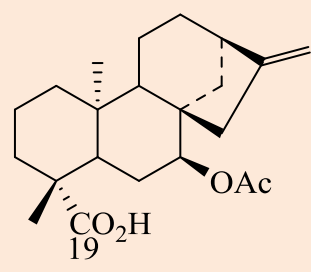

20<smiles>C=C1CC23CC1CCC2[C@@]12CC[C@@H](O)C(C)(C(=O)O)C1CC2OC(=O)O3</smiles>

21<smiles>C=C1CC23CC1CCC2[C@@H]1C[C@H](O)[C@@H](O)C(C)(C(=O)O)C1CC3OC(C)=O</smiles>

22

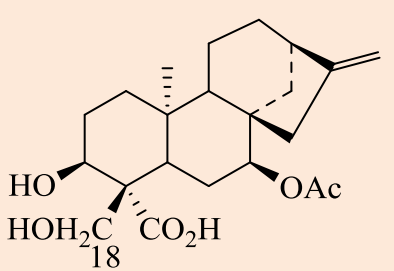

23

Figura 12. Estrutura química de 17 e dos produtos de biotransformação 18-23 por G. fujikuroi

A biotransformação de xenobióticos independe de relações estruturais entre o material de partida e o fungo, o que é de interesse para a geração de derivados com diversidade estrutural. Como exemplo, apresenta-se a biotransformação da artemisinina (24) pelo fungo Aspergillus niger. A artemisinina é um sesquiterpeno natural isolado de Artemisia annua utilizado para o tratamento da malária. A biotransformação desta substância por $A$. niger levou à obtenção de quatro produtos (25-28), algumas das quais com estruturas químicas muito inovadoras, como mostrado na Figura $13 .{ }^{89}$

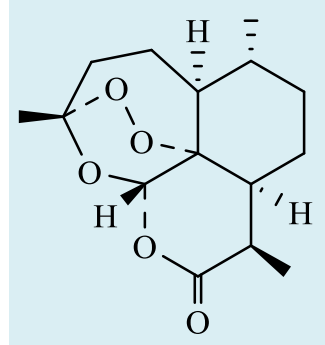

24

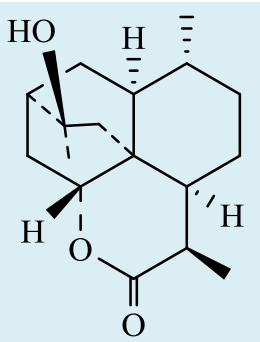

25<smiles>CC(=O)O[C@H]1OC(=O)[C@H](C)[C@@H]2CC[C@H](C)[C@H]3CCO[C@]123</smiles>

26

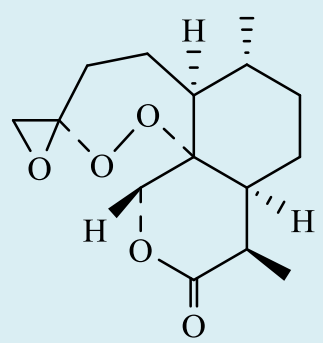

27

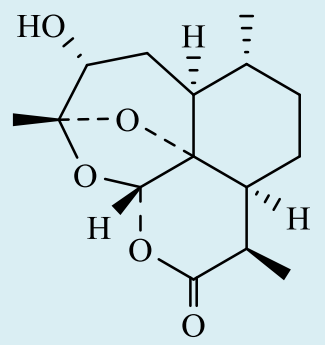

28

Figura 13. Estrutura química da artemisinina (24) e dos produtos $3 \beta$-hidroxi-4,12-epoxi-1-

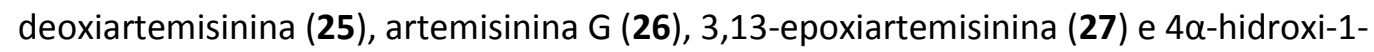
deoxiartemisinina (28) 
A utilização de fungos em biotransformação de xenobióticos é uma importante ferramenta para obtenção de novos compostos bioativos (Tabela 1), especialmente quando o material de partida administrado ao fungo é uma substância pouco funcionalizada, já que a biotransformação mais comum produzida por fungos é a hidroxilação de carbonos inativados. Um exemplo interessante é a biotransformação do 20-(S)-protopanaxatriol (29) por Mucor racemosus. ${ }^{90}$ Os produtos desta biotransformação (30-35) mostraram que o fungo funcionalizou diversas posições do esqueleto (Figura 14). Quando submetido ao bioensaio de atividade citotóxica contra quatro linhagens de células cancerígenas (K562, SH-SY5Y, HepG2, e MCF-7), o produto 34 apresentou atividade citotóxica maior do que o material de partida contra as quatro linhagens de células tumorais testadas. Para a linhagem MCF-7, o material de partida apresentou $\mathrm{CIM}=27,6 \mu \mathrm{M}$, enquanto que o produto 33 apresentou $\mathrm{CIM}=7,1 \mu \mathrm{M}$, um indicativo de que a introdução de uma hidroxila na posição $7 \alpha$ pelo fungo foi importante para aumentar a citotoxicidade deste composto.

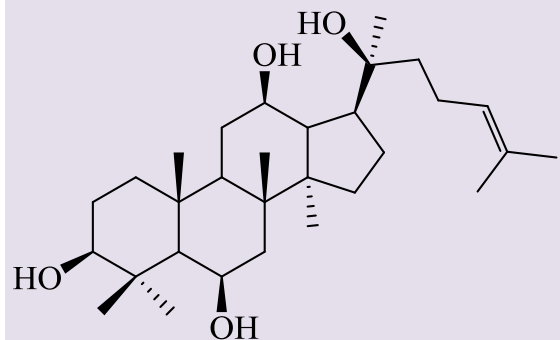

29

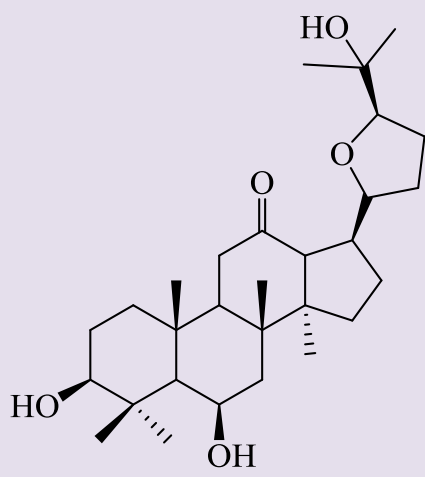

33

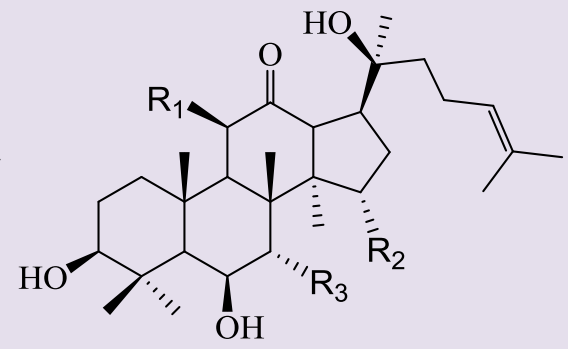

$30 \mathrm{R}_{1}=\mathrm{R}_{2}=\mathrm{R}_{3}=\mathrm{H}$

$31 \mathrm{R}_{1}=\mathrm{OH}, \mathrm{R}_{2}=\mathrm{R}_{3}=\mathrm{H}$

$32 \mathrm{R}_{2}=\mathrm{OH}, \mathrm{R}_{1}=\mathrm{R}_{3}=\mathrm{H}$

$34 \mathrm{R}_{1}=\mathrm{R}_{2}=\mathrm{H}, \mathrm{R}_{3}=\mathrm{OH}$

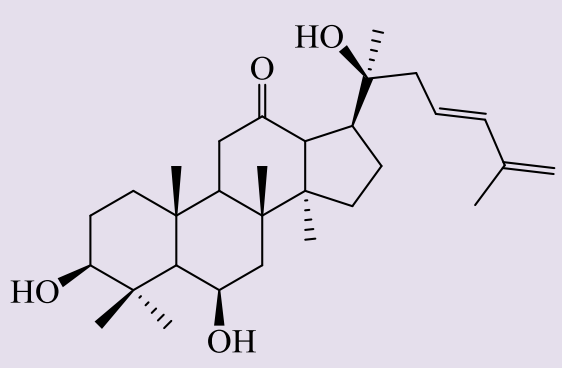

35

Figura 14. Estrutura química do 20-(S)-protopanaxatriol (29) e de análogos produzidos por biotransformação 
Tabela 1. Exemplos de fungos capazes de biotransformar xenobióticos

\begin{tabular}{|c|c|c|}
\hline $\begin{array}{l}\text { Classe dos } \\
\text { substratos }\end{array}$ & Fungos & Referência \\
\hline \multirow[b]{2}{*}{ Monoterpenos } & Lasiodiplodia, Mucor, Trichoderma & 91 \\
\hline & $\begin{array}{c}\text { Absidia, Aspergillus, Botrytis, Cephalosporium, Corynespora, } \\
\text { Curvularia, Diplodia, Fusarium, Giberella, Glomerella, } \\
\text { Penicillium, Rhizoctonia, Rhizopus }\end{array}$ & 92 \\
\hline \multirow{4}{*}{ Sesquiterpenos } & Aspergillus & 89 \\
\hline & Botrytis & 93 \\
\hline & Cunninghamella & 94 \\
\hline & Mucor & 95 \\
\hline \multirow[t]{3}{*}{ Diterpenos } & Absidia, Rhizopus & 96 \\
\hline & Cunninghamella & 97 \\
\hline & Giberella & 98 \\
\hline \multirow[t]{2}{*}{ Triterpenos } & Cunninghamella, Mucor & 99 \\
\hline & Rhizomucor & 100 \\
\hline \multirow{2}{*}{ Esteroides } & Cunninghamella & 101 \\
\hline & Rhizopus & 83 \\
\hline \multirow{2}{*}{ Policetideos } & Beauveria & 102 \\
\hline & Paecilomyces & 103 \\
\hline \multirow{2}{*}{ Flavonoides } & Absidia & 104 \\
\hline & Aspergillus, Cunninghamella, Penicillium & 105 \\
\hline \multirow{2}{*}{ Alcaloides } & Chaetosphaeria, Fusarium, Gliocladium, Plectosporium & 106 \\
\hline & Paecilomyces & 107 \\
\hline
\end{tabular}

Embora a humanidade tenha utilizado fungos por séculos para a biotransformação de compostos, só recentemente, com a ajuda da química, tem sido possível controlar a produção, desenvolver novos biocatalisadores com alta estabilidade e produtividade e desenvolver novas condições operacionais, o que faz com que, a cada dia, a indústria se beneficie mais destes microorganismos, suas enzimas e metabólitos. ${ }^{108}$ Com estes avanços, a indústria farmacêutica pôde incorporar algumas etapas sintéticas seletivas, usando micro-organismos ou enzimas isoladas deles, para a produção de diversos fármacos de grande utilidade e alto valor agregado, como os antidiabéticos saxagliptina e sitagliptina, o antidepressivo buspirone, o antiviral atazanavir, entre outros. ${ }^{109}$ No caso da saxagliptina, fármaco utilizado no controle glicêmico de pacientes com diabetes tipo II, o qual foi desenvolvido pela Bristol-Myers Squibb e aprovado comercialmente em 2009, foi realizada uma conversão de uma cetona em amina, utilizando uma forma modificada de fenilalanina desidrogenase clonada da bactéria Thermoactinomyces intermedius e expressa no fungo Pichia pastoris, como também na bactéria Escherichia coli (Figura 15). A reação biocatalisada ocorreu de forma 
regiosseletiva e principalmente, enantiosseletiva, formando somente o produto com a amina na posição $\beta$. Essa etapa sintética biocatalisada com a enzima expressada em Escherichia coli apresentou 98
$\%$ de rendimento com $100 \%$ de excesso enantiomérico e, atualmente, está sendo usada para a produção industrial da saxagliptina. ${ }^{109}$

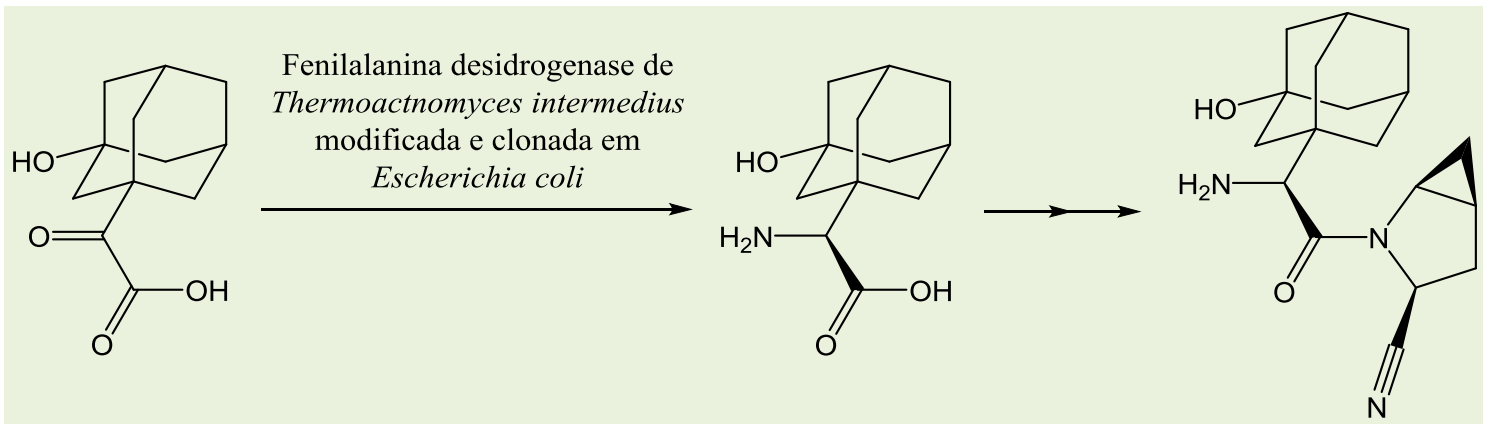

Figura 15. Aminação enzimática redutiva na síntese da saxagliptina

Outro fármaco de elevada relevância produzido através do processo de biocatálise é o antiviral atazanavir, usado no tratamento de pacientes portadores do vírus do HIV. Um intermediário quiral chave na síntese do atazanir foi produzido a partir da redução diasterosseletiva utilizando cepas das bactérias do gênero Rhodococcus e Brevibacterium, e de fungos do gênero
Hansenula. Após três espécies de Rhodococcus apresentarem rendimentos acima de $90 \%$, foi desenvolvida uma metodologia de biotransformação catalisada por Rhodococcus erythopolis (Figura 16), a qual apresentou a redução diasterosseletiva com $95 \%$ de rendimento e $99,4 \%$ de excesso enantiomérico. ${ }^{109}$

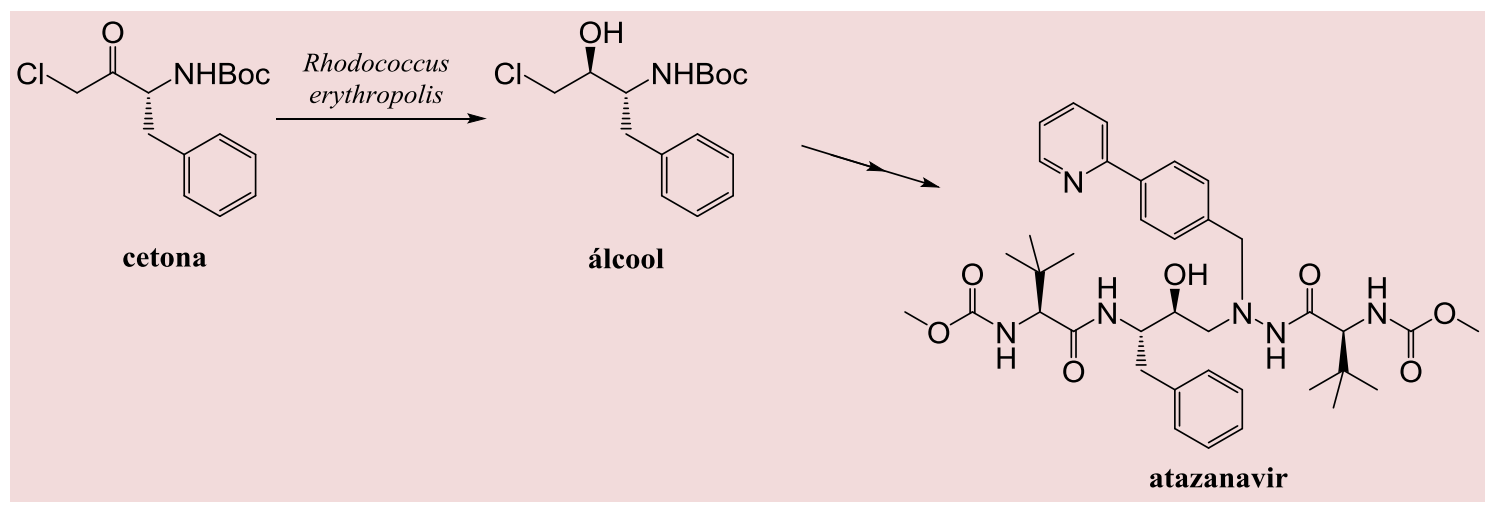

Figura 16. Uso de biotransformação para a síntese do Atazanavir

Além da produção de fármacos utilizando processos biocatalíticos, fungos e enzimas têm sido amplamente empregados para a produção de compostos de alto valor agregado na química fina, como flavorizantes e aromatizantes, com bons rendimentos. ${ }^{110}$

\section{Biorremediação}

A biorremediação é um processo biotecnológico utilizado para a remoção ou redução de poluentes dos ambientes aquáticos e terrestres impactados, visando à 
restauração da qualidade ambiental utilizando plantas, algas ou micro-organismos de ocorrência natural, como fungos. ${ }^{111} \mathrm{O}$ uso de fungos em biorremediação é vantajoso devido à sua elevada tolerância a poluentes, penetração no solo através de micélio, ${ }^{112}$ capacidade de resistir aos efeitos tóxicos de compostos xenobióticos e de degradar um grande número de compostos estruturalmente diferentes. A biorremediação pode ser realizada no local afetado pelo xenobiótico, o que diminui o custo deste processo. Além disso, conforme mencionado anteriormente, fungos não dependem da sazonalidade para o seu crescimento, uma vez que podem ser cultivados durante todo o ano e o processo pode ser otimizado modificando as condições de crescimento. ${ }^{113}$

A metodologia mais comum para a execução do processo de biorremediação por fungos utiliza células fúngicas em crescimento, em que a biomassa do fungo se desenvolve juntamente com o contaminante a ser degradado ou removido. Entretanto, usando esta abordagem, reagentes presentes nos meios de cultura podem interagir com o contaminante, alterando a sua disponibilidade no sistema e gerando interferências no processo. Assim, tem emergido a alternativa de serem utilizadas "células em repouso", tecnologia na qual a biomassa fúngica, após desenvolvimento, é separada por filtração e lavada, para a remoção completa do meio de cultura. ${ }^{114}$ Posteriormente, essa biomassa é adicionada diretamente à solução contendo o contaminante para se efetuar a biorremediação.

Outra metodologia promissora no nível laboratorial de utilização da biomassa fúngica no tratamento de água contaminada é através da formação de pellets (porções densas de micélios) de fungos autoimobilizados em um biorreator. Com esse método, evitam-se as dificuldades práticas e técnicas normalmente encontradas com o micélio disperso, pois a utilização dos pellets fúngicos facilita a separação da biomassa fúngica, proporcionando sua reutilização e, portanto, um processo contínuo. Além disso, não ocorre aderência em nenhuma parte do reator, o que diminui a possibilidade de seu entupimento e também facilita a recuperação do produto. Por exemplo, foi relatado que a utilização de pellets é um processo mais eficiente de remoção de cor e compostos aromáticos de águas residuais em fábrica de celulose, em comparação com outras formas de crescimento da espécie fúngica Trametes versicolor. ${ }^{115}$

Os fungos são capazes de biorremediar tanto contaminantes inorgânicos quanto orgânicos. Dentre os contaminantes inorgânicos, os metais são muito preocupantes devido ao volume em que são depositados no ambiente em decorrência do aumento das atividades industriais e agrícolas. Além disso, muitos são tóxicos (mercúrio, arsênio, chumbo e outros), mesmo em concentrações muito baixas, podendo causar efeitos carcinogênicos e mutagênicos. ${ }^{116} \mathrm{~A}$ biorremedição de metais por fungos, muito relatada na literatura envolve mecanismos que podem ser dependentes do metabolismo ou não. ${ }^{117}$ Quando depende do metabolismo, é necessário que as células fúngicas estejam vivas, pois necessita de energia para ativar o metabolismo e efetuar o transporte do metal através da membrana celular para o interior da célula, onde é convertido em formas inofensivas ou complexado. Outra forma de biorremediação dependente do metabolismo é a precipitação, processo que ocorre quando o fungo produz compostos que são lançados extracelularmente que se ligam ou reagem com os metais, levando à sua precipitação.

No processo que independe do metabolismo, as células fúngicas podem estar vivas ou mortas. Envolve os mecanismos de adsorção, complexação e troca iônica. ${ }^{117} \mathrm{O}$ processo de biorremediação fúngica por adsorção envolve interações de van der Waals e eletrostáticas, em que ocorre sorção dos metais na superfície da célula, concentrando-se em maior quantidade na interface da biomassa do 
fungo. Na parede celular do fungo existem proteínas, lipídeos e polissacarídeos, nos quais existem grupos funcionais, que são sítios de ligações para os metais, como os grupos hidroxila, carboxila, sulfato, acetamido, amido e amino. Esses grupos são capazes de captar os íons metálicos melhorando o processo. ${ }^{118}$ De acordo com Kapoor e Viraraghaven (1995), o processo de adsorção de metais depende de fatores como tempo de contato entre o metal presente em uma solução e a biomassa fúngica, $\mathrm{pH}$, temperatura da solução, concentração inicial dos metais, tipo de metal e concentração da biomassa. ${ }^{119}$

O processo de troca iônica pode ocorrer em toda a superfície da biomassa do fungo. Os metais contaminantes presentes em solução deslocam os íons com a mesma carga que está presente na superfície da biomassa. Os íons metálicos de maior afinidade conseguem trocar de posição com o íon do sítio ativo. Na complexação ocorre interação dos metais com os grupos funcionais presentes na superfície da biomassa do fungo, formando complexos. Esse mecanismo envolve a coordenação do íon metálico com o grupo funcional presente na parede celular da biomassa fúngica. ${ }^{117} \mathrm{Em}$ alguns casos de biorremediação de íons, é possível melhorar a efetividade do processo, submetendo-se a biomassa a um pré-tratamento em meio básico, para se remover lípidos e proteínas (substâncias que mascaram os sítios de ligação nos quais os metais se ligam) ou inutilizar enzimas autolíticas presentes na biomassa fúngica. ${ }^{118}$

Iram et al. (2015) relataram a remoção dos metais $\mathrm{Cu}^{+2}$ e $\mathrm{Pb}^{+2}$ pelas espécies de fungos Aspergillus flavus e $A$. niger em uma ampla faixa de temperatura e $\mathrm{pH}$ básico. ${ }^{120} \mathrm{~A}$ remoção do íon metálico $\mathrm{Cd}^{+2}$ em solução aquosa foi obtida por Netpae (2015), ${ }^{121}$ após o tratamento da biomassa do fungo Humicola sp. com $\mathrm{HNO}_{3}$ e $\mathrm{NaOH}(96,35$ e $83,32 \%$, respectivamente). Hassan e El-Kassas (2012) relataram um aumento de 1,86 vezes na remoção do íon metálico $\mathrm{Cd}^{+2}$ pelo fungo Aspergillus cristatus, após a otimização das condições de cultura para a produção de biomassa fúngica. ${ }^{122}$

Além de metais, os fungos conseguem degradar ou remover contaminantes orgânicos como pesticidas, ${ }^{123}$ corantes ${ }^{124} \mathrm{e}$ outros. ${ }^{35}$ A destoxificação de pesticidas organofosforados e carbamatos pelos fungos ocorre geralmente através de enzimas fosfotriesterases e carboxilesterases, gerando metabólitos menos tóxicos que o composto de partida. ${ }^{125}$ Exemplos de sucesso ocorreram com o fungo Aspergillus versicolor, que foi capaz de degradar $71,94 \%$ do pesticida triclosan em meio semissintético, ${ }^{126}$ enquanto o fungo Trametes versicolor, crescido em casca de arroz degradou 55,1\% do pesticida carbofurano. Neste caso, o produto de biotransformação obtido mostrou-se $89 \%$ menos tóxico quando comparado ao carbofurano. ${ }^{127}$

Outra classe de contaminantes orgânicos importantes como alvo de biorremediação, devido ao seu potencial carcinogênico e mutagênico, são os hidrocarbonetos aromáticos policíclicos. ${ }^{128}$ Neste processo, de biorremediação são acumulados no meio intracelular e subsequentemente degradados em altas porcentagens, chegando a níveis de degradação de 95\%, como ocorre na degradação do fluoranteno por enzimas do fungo Pleurotus eryngii F032, após a otimização das condições de cultivo. ${ }^{129}$

Os corantes também são contaminantes orgânicos amplamente presentes no ambiente devido ao crescimento das indústrias têxteis, que consomem uma matriz extensa e diversificada de produtos químicos na forma de corantes. Em diversos casos, o mecanismo principal de remoção de corantes azo ocorre por biosorção, como relatado para os fungos $A$. flavus e Alternaria spp.. ${ }^{130} \mathrm{~A}$ biorremediação do corante verde de malaquita pelos fungos $A$. niger $\mathrm{e}$ Phanerochaete chrysosporium chegou a $72,77 \%$ e $83,25 \%$, respectivamente. ${ }^{131}$ Ao se utilizar o fungo Myrothecium roridum, a biorremediação foi superior a $90 \%$, graças ao mecanismo de oxidação enzimática por lacases produzidas pelo fungo. ${ }^{132}$ Na Figura 17 são ilustradas as metodologias utilizadas 
nos processos de biorremediação (adsorção e fungos. degradação) e biotransformação utilizando
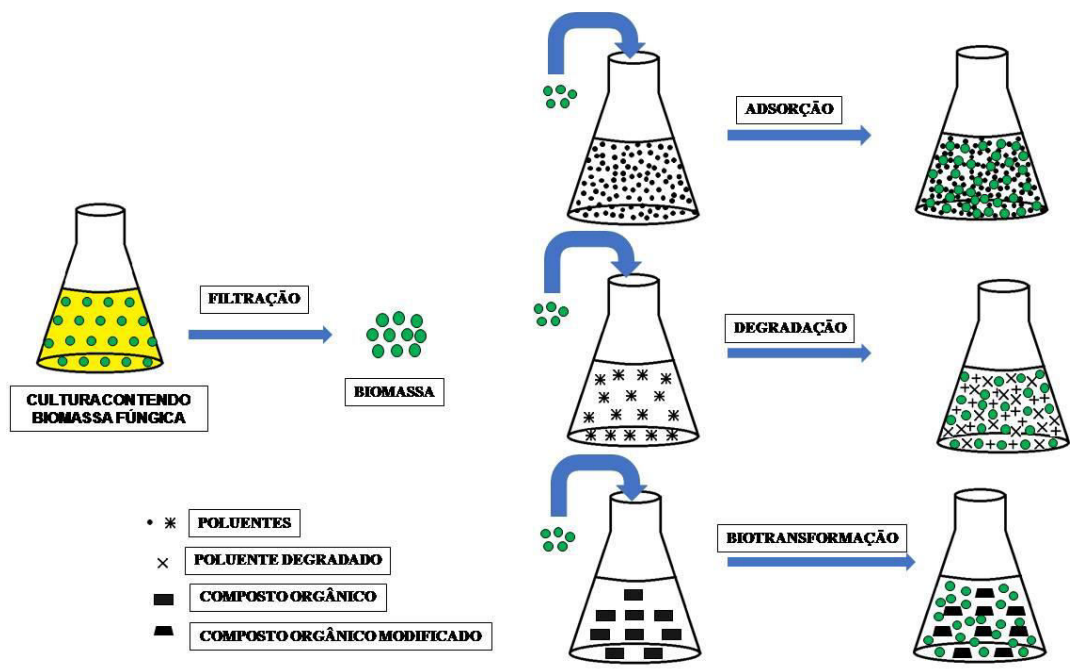

Figura 17. Ilustração dos processos de biorremediação por adsorção e degradação, e do processo de biotransformação

\section{Conclusão e perspectivas}

$\mathrm{Na}$ química moderna, novas oportunidades para a utilização de fungos tem despontado nas mais diversas áreas, como na produção de biocombustíveis e na síntese partículas de prata nanocristalinas, ${ }^{133}$ onde fungos tem sido o organismo de escolha para a síntese de nanomateriais. ${ }^{134}$ Além disso, na área de química de produtos naturais, a mudança da abordagem experimental clássica para a inserção direta dos extratos em espectrômetro de massas para screenings inteligentes do metaboloma tem agilizado o acesso e a comparação de perfis metabólicos de um elevado número de espécies fúngicas para o mapeamento de novos metabólitos que possam ter uso biotecnológico. A complementaridade entre química e microbiologia é uma experiência de sucesso, consistindo em um campo desafiador para novos pesquisadores, em busca soluções criativas para um mundo com novas expectativas de uma química mais verde, uma vida mais saudável e medicamentos mais eficazes.

\section{Agradecimentos}

À FAPEMIG e CNPq, por bolsas e financiamento de projetos. À Alice F. da SilvaHughes e Gesiane S. Lima pela produção e disponibilização das fotografias utilizadas para ilustrar esta revisão. À CAPES - Bolsista da CAPES - Proc. n BEX 6447/15-5.

\section{Referências Bibliográficas}

${ }^{1}$ Maia, L. C.; Carvalho Júnior, A. A. D.; Cavalcanti, L. D. H.; Gugliotta, A. D. M.; Drechsler-Santos, E. R.; Santiago, A. L. D. A.; Cáceres, M. E. S.; Gibertoni, T. B.; Aptroot, A.; Giachini, A. J.; Soares, A. M. S.; Silva, A. C. G.; Magnago, A. C.; Goto, B. T.; Lira, C. R. S.; Montoya, C. A. S.; Pires-Zottarelli, C. L. A.; da Silva, D. K. A.; Soares, D. J.; Rezende, D. H. C.; Luz, E. D. M. N.; Gumboski, E. L.; Wartchow, F.; Karstedt, F.; Freire, F. M.; Coutinho, F. P.; de Melo, G. S. N.; Sotão, H. M. P.; Baseia, I. G.; Pereira, J.; de Oliveira, J. J. S.; Souza, J. F.; Bezerra, J. L.; Araujo Neta, L. S.; Pfenning, L. H.; Gusmão, L. F. P.; Neves, M. A.; Capelari, 
M.; Jaeger, M. C. W.; Pulgarín, M. P.; Menolli Junior, N.; de Medeiros, P. S.; Friedrich, R. C. S.; Chikowski, R. S.; Pires, R. M.; Melo, R. F.; da Silveira, R. M. B.; Urrea-Valencia, S.; Cortez, V. G.; da Silva, V. F. Diversity of Brazilian Fungi. Rodriguésia 2015, 66, 1033. [CrossRef]

${ }^{2}$ Maia, L. C.; Carvalho Junior, A. A. Introdução: os fungos do Brasil. Em: Forzza, R. C.; Baumgratz, J. F. A.; Bicudo, C. E. M.; Carvalho Jr., A. A. A.; Costa, A.; Costa, D. P.; Hopkins, M.; Leitman, P. M.; Lohmann, L. G.; Maia, L. C.; Martinelli, G.; Menezes, M.; Morim, M. P.; Coelho, M. A. N.; Peixoto, A. L.; Pirani, J. R.; Prado, J.; Queiroz, L. P.; Souza, V. C.; Stehmann, J. R.; Sylvestre, L. S.; Walter, B. M. T.; Zappi, D., eds.; Andrea Jakobsson Estúdio: Rio de Janeiro, 2010. [Link]

${ }^{3}$ Hibbett, D.; Binder, M.; Bischoff, J. F.; Blackwell, M.; Cannon, P. F.; Eriksson, O. E.; Huhndorf, S.; James, T.; Kirk, P. M.; Lücking, R.; Thorsten, L. H.; Lutzoni, F.; Matheny, P. B.; McLaughlin, D. J.; Powell, M. J.; Redhead, S.; Schoch, C. L.; Spatafora, J. W.; Stalpers, J. A.; Vilgalys, R.; Aime, M. C.; Aptroot, A.; Bauer, R.; Begerow, D.; Benny, G. L.; Castlebury, L. A.; Crous, P. W.; Dai, Y. C.; Gams, W.; Geiser, D. M.; Griffith, G. W.; Gueidan, C.; Hawksworth, D. L.; Hestmark, G.; Hosaka, K.; Humber, R. A.; Hyde, K. D.; Ironside, J. E.; Kõljalg, U.; Kurtzman, C. P.; Larsson, K. H.; Lichtwardt, R.; Longcore, J.; Miadlikowska, J.; Miller, A.; Moncalvo, J. M.; MozleyStandridge, S.; Oberwinkler, F.; Parmasto, E.; Reeb, V.; Rogers, J. D.; Roux, C.; Ryvarden, L.; Sampaio, J. P.; Schüssler, A.; Sugiyama, J.; Thorn, R. G.; Tibell, L.; Untereiner, W. A.; Walker, C.; Wang, Z.; Weir, A.; Weiss, M.; White, M. M.; Winka, K.; Yao, Y. J.; Zhang, N. A higher-level phylogenetic classification of the Fungi. Mycological Research 2007, 111, 509. [CrossRef] [PubMed]

${ }^{4}$ Kurtzman, C.; Fell, J. W.; Boekhout, T.; The Yeasts: A Taxonomic Study, 5a. ed., Elsevier Science: Oxford, 2011. [Link]

${ }^{5}$ Abrão, F. O.; Duarte, E. R.; Freitas, C. E. S.; Vieira, E. A.; Geraseev, L. C., da Silva-Hughes, A. F., Rosa, C. A.; Rodrigues, N. M. Characterization of fungi from ruminal fluid of beef cattle with different ages and raised in tropical lignified pastures. Current microbiology 2014, 69, 649. [CrossRef] [PubMed]

${ }^{6}$ Silva-Hughes, A. F.; Wedge, D. E.; Cantrell, C. L.; Carvalho, C. R.; Pan, Z.; Moraes, R. M.; Madoxx, V. L.; Rosa, L. H. Diversity and antifungal activity of the endophytic fungi associated with the native medicinal cactus Opuntia humifusa (Cactaceae) from the United States. Microbiological research 2015, 175, 67. [CrossRef] [PubMed]

${ }^{7}$ Morais, C. G.; Lara, C. A.; Oliveira, E. S.; Péter, G.; Dlauchy, D.; Rosa, C. A. Spencermartinsiella silvicola sp. nov., a yeast species isolated from rotting wood. International journal of systematic and evolutionary microbiology 2016, 66, 604. [CrossRef] [PubMed]

${ }^{8}$ Wieser, A.; Schneider, L.; Jung, J.; Schubert, S. MALDI-TOF $\mathrm{MS}$ in microbiological diagnostics-identification of microorganisms and beyond (mini review). Applied microbiology and biotechnology 2012. 93, 965. [CrossRef] [PubMed]

${ }^{9}$ Li, W.; Xu, J.; Li, F.; Xu, L.; Li, C. A new antifungal isocoumarin from the endophytic fungus Trichoderma Sp. 09 of Myoporum bontioides A. gray. Pharmacognosy Magazine 2016a, 12, 259. [CrossRef] [PubMed]

${ }^{10}$ Demain, A. L.; Sanchez, S. Microbial drug discovery: 80 years of progress. The Journal of Antibiotics 2009, 62, 5. [CrossRef] [PubMed]

${ }^{11}$ Newman, D. J.; Cragg, G. M. Natural products as sources of new drugs from 1981 to 2014. Journal of Natural Products 2016, 79, 629. [CrossRef] [PubMed]

${ }^{12}$ Almeida, F. O. A arqueologia dos fermentados: a etílica história dos TupiGuarani. Estudos avançados 2015, 29, 87. [CrossRef]

${ }^{13}$ Ross, R. P.; Morgan, S.; Hill, C. Preservation and fermentation: past, present and future. International Journal of Food Microbiology 2002, 79, 3. [CrossRef] [PubMed]

${ }^{14}$ Bourdichon, F.; Casaregola, S.; Farrokh, C.; Frisvad, J. C.; Gerds, M. L.; Hammes, W.P.; Harnett, J.; Huys, G.; Laulund, S.; Ouwehand, A.; Powell, I. B.; Prajapati, J.B.; Seto, Y.; Schure, E. T.; Boven, A. V.; Vankerckhoven, V.; Zgoda, A.; Tuijtelaars, S.; Hansen, E. B. Food fermentations: microorganisms with 
technological beneficial use. International Journal of Food Microbiology 2012, 154, 87. [CrossRef] [PubMed]

${ }^{15}$ Gonçalves, F. A. G.; Colen, G.; Takahashi, J. A. Yarrowia lipolytica and its multiple applications in the biotechnological industry. The Scientific World Journal 2014, 2014, 1. [CrossRef] [PubMed]

${ }^{16}$ Tamang, J. P. Em Diversity of fermented foods; Tamang, J. P.; Kailasapathy, K., eds.; CRC Press: Boca Raton, 2010, cap. 2. [CrossRef]

${ }^{17}$ Nout, M. J. R.; Aidoo, K. E. Em Asian fungal fermented food; Hofrichter, M., ed.; SpringerVerlag: Berlin, 2010, cap. 2. [CrossRef]

${ }^{18}$ Tamang, J. P.; Watanabe, K.; Holzapfel, W. $\mathrm{H}$. Review: Diversity of microorganisms in global fermented foods and beverages. Frontiers in Microbiology 2016, 7, 377. [CrossRef] [PubMed]

${ }^{19}$ Simova, E.; Beshkova, D.; Angelov, A.; Hristozova, T.; Frengova, G.; Spasov, Z. Lactic acid bacteria and yeasts in kefir grains and kefir made from them. Journal of Industrial Microbiology and Biotechnology 2002, 28, 1. [CrossRef] [PubMed]

${ }^{20}$ Lacerda, I. C. A.; Miranda, R. L.; Borelli, B. M.; Nunes, A. C.; Nardi, R. M. D.; Lachance, M. A.; Rosa, C. A. Lactic acid bacteria and yeasts associated with spontaneous fermentations during the production of sour cassava starch in Brazil. International Journal of Food Microbiology 2005, 105, 213. [CrossRef] [PubMed]

${ }^{21}$ Padonou, S. W.; Nielsen, D. S.; Akissoe, N. H.; Hounhouigan, J. D.; Nago, M. C.; Jakobsen, M. Development of starter culture for improved processing of lafun, an african fermented cassava food product. Journal of Applied Microbiology 2010, 109, 1402. [CrossRef] [PubMed]

${ }^{22}$ Aidoo, K. E.; Nout, M. J. R. Em Functional yeasts and molds in fermented foods and beverages; Tamang, J. P.; Kailasapathy, K., eds.; CRC Press, 2010, cap. 4. [CrossRef]

${ }^{23}$ Perry, K. S. P. Queijos: aspectos químicos, bioquímicos e microbiológicos. Química Nova 2004, 27, 293. [CrossRef]

2424 Babu, P.D.; Bhakyaraj, R.; Vidhyalakshmi, R. A low cost nutritious food "tempeh"- a review. World Journal of Dairy \& Food Sciences 2009, 4, 22. [Link]

${ }^{25}$ Mapari, S. A. S.; Thrane, U.; Meyer, A. S. Fungal polyketide azaphilone pigments as future natural food colorants?. Trends in Biotechnology 2010, 28, 300. [CrossRef] [PubMed]

2626 Dufossé, L.; Fouillaud, M.; Carol, Y.; Mapari, S. A. S.; Sutthiwong, N. Filamentous fungi are large-scale producers of pigments and colorants for the food industry. Current Opinion in Biotechnology 2014, 26, 56. [CrossRef] [PubMed]

${ }^{27}$ Shahid, M.; Islam, S., Mohammad, F. Recent advancements in natural dye applications: a review. Journal of Cleaner Production 2013, 310. [CrossRef]

2828 Boa, E. Wild edible fungi: a global overview of their use and importance to people. FAO: Roma, 2004. [Link]

${ }^{29}$ Park, Y. K.; Ikegaki, M.; Alencar, S. M.; Aguiar, C. L. Determinação da concentração de $\beta$-glucano em cogumelo Agaricus bazei Murill por método enzimático. Ciência $e$ Tecnologia de Alimentos 2003, 3, 312. [CrossRef]

${ }^{30}{ }^{30}$ Wang, X. M.; Zhang, J.; Wu, L. H.; Zhao, Y. L.; Li, T.; Li, J. Q.; Wang, Y. Z.; Liu, H. G. A mini-review of chemical composition and nutritional value of edible wild-grown mushroom from China. Food Chemistry 2014a, 15, 279. [CrossRef] [PubMed]

${ }^{31}$ Silva, L. C.; Pereira, A. M.; Takahashi, J. A.; Carvalho, S. A. Teores de fibra alimentar em sete espécies de cogumelos comestíveis. Higiene Alimentar 2013, 27, 679. [CrossRef]

${ }^{32}$ Lee, K. H.; Morris-Natschke, S. L.; Yang, X.; Huang, R.; Zhou, T.; Wu, S. F.; Shi, Q.; Itokawa, $\mathrm{H}$. Recent progress of research on medicinal mushorroms, foods, and other herbal products used in tradicional Chinese medicine. Journal of Traditional and Complementary Medicine 2012, 2, 84. [CrossRef] [PubMed]

${ }^{33}$ Giavasis, I. Bioactive fungal polysaccharides as potential functional ingredients in food and nutraceuticals. Current Opinion in Biotechnology 2014, 26, 162. [CrossRef] [PubMed] 
${ }^{34}$ Bishop, K. S.; Kao, C. H. J.; Xu, Y.; Glucina, M. P.; Paterson, R. M.; Ferguson, L. R. From 2000 years of Ganoderma lucidum to recent developments in nutraceuticals. Phytochemistry 2015. [CrossRef] [PubMed] ${ }^{35}$ Wang, H. -W.; Zhang, W.; Su, C. -L.; Zhu, H.; Dai, C. -C. Biodegradation of the phytoestrogen luteolin by the endophytic fungus Phomopsis liquidambari. Biodegradation 2015, 26, 197. [CrossRef]

${ }^{36}$ Jenke-Kodama, H.; Muller, R.; Dittmann, E. Em Evolutionary mechanisms underlying secondary metabolite diversity; Petersen, F.; Amstutz, eds.; Birkhauser Verlag: Basel, 2008, cap. 3. [Link]

${ }^{37}$ Gunatilaka, A. A. L. Natural products from plant-associated microorganisms: distribution, structural diversity, bioactivity, and implications of their occurrence. Jounal of Natural Products 2006, 69, 509. [CrossRef] [PubMed]

${ }^{38}$ Newman, D. J.; Cragg, G. M. Natural products as sources of new drugs over the 30 years from 1981 to 2010. Journal of Natural Products 2012, 75, 311. [CrossRef] [PubMed] ${ }^{39}$ Singh, S. B.; Pelaez, F.; Em Biodiversity, chemical diversity and drug discovery; Petersen, F.; Amstutz, R., Birkhauser Verlag: Basel, 2008, cap. 4. [Link]

${ }^{40}$ Laupacis, A.; Keown, P. A.; Ulan, R. A.; Mckenzie, N. e Stiller, C. R. Cyclosporin A: A powerful immunosuppressant. Canadian Medical Association Journal 1982, 126, 1041. [PubMed]

${ }^{41}$ Mahajan, G.; Balachandran, L. Biodiversity in production of antibiotics and other bioactive compounds. Advances in Biochemical Engineering/Biotechnology 2015, 147, 37. [CrossRef] [PubMed]

${ }^{42}$ Butler, M. S.; Fontaine, F.; Cooper, M. A. Natural Product Libraries: Assembly, Maintenance, and Screening. Planta Medica 2014, 80, 1161. [CrossRef] [PubMed]

${ }^{43}$ Bode, H. B.; Bethe, B.; Hofs, R.; Zeeck, A. Big effects from small changes: Possible ways to explore nature's chemical diversity. Chembiochem 2002, 3, 619. [CrossRef] [PubMed]

${ }^{44}$ Wang, W. -J.; Li, D. -Y.; Li, Y. -C.; Hua, H. M.; Ma, E. -L.; Li, Z. -L. Caryophyllene sesquiterpenes from the marine-derived fungus Ascotricha sp. ZJ-M5 by the One Strain-Many Compounds strategy. Journal of Natural Products 2014b, 77, 1367. [CrossRef] [PubMed]

${ }^{45}$ Xie, L. -R.; Li, D. - Y.; Li, Z. -L.; Hua, H. -M.; Wang, P. -L.; Wu, X. A new cyclonerol derivative from a marine-derived fungus Ascotricha sp. ZJ-M-5. Natural Product Research 2013, 27, 847. [CrossRef] [PubMed] ${ }^{46}$ Shwab, E. K.; Keller, N. P. Regulation of secondary metabolite production in filamentous ascomycetes. Mycological research 2008, 112, 225. [CrossRef] [PubMed]

${ }^{47}$ Takahashi, J. A.; Gomes, D. C.; Lyra, F. H.; dos Santos, G. F. Em Modulation of Fungal Secondary Metabolites Biosynthesis by Chemical Epigenetics; Deshmukh, S. K.; Misra, J. K.; Tewari, J. P.; Papp, T., eds.; CRC Press: Boca Raton, 2016, cap. 6. [Link]

${ }^{48}$ Takahashi, J. A.; Teles, A. P. C.; Bracarense, A. A. P.; Gomes, D. C. Classical and epigenetic approaches to metabolite diversification in filamentous fungi. Phytochemistry Reviews 2013, 12, 773. [CrossRef]

${ }^{49}$ Williams, R. B.; Henrikson, J. C.; Hoover, A. R.; Lee, A. E.; Cichewicz, R. H. Epigenetic remodeling of the fungal secondary metabolome. Organic \& Biomolecular Chemistry 2008, 6, 1895. [CrossRef] [PubMed]

${ }^{50}$ Teles, A. P. C; Takahashi, J. A. Paecilomide, a new acetylcholinesterase inhibitor from Paecilomyces lilacinus. Microbiological Research 2013, 168, 204. [CrossRef] [PubMed]

${ }^{51}$ Li, Y. F.; Wu, X. B.; Niaz, S. I.; Zhang, L. H.; Huang, Z. J.; Lin, Y. C.; Li, J.; Liu, L. Effect of culture conditions on metabolites produced by the crinoid-derived fungus Aspergillus ruber 1017. Natural Product research, 2016b, in press. [CrossRef] [PubMed]

${ }^{52}$ Peyrat, L. -A; Eparvier, V.; Eydoux, C.; Guillemot, J. -C.; Litaudon, M.; Stien, D. Betulinic acid, the first lupane-type triterpenoid isolated from both a Phomopsis sp. and its host plant Diospyros carbonaria Benoist. Chemistry \& Biodiversity 2016, 14, e1600171. [CrossRef] [PubMed]

${ }^{53}$ Huang, R.; Wang, T.; Xie, X. S.; Ma, K. X; Fang, X. W.; Wu, S. H. Secondary metabolites 
from an endophytic fungus Nigospora $s p$. Chemistry of Natural Compounds 2016, 52, 697. [CrossRef]

${ }^{54}$ Zhang, A. H.; Tan, R.; Jiang, N.; Yusupu, K.; Wang, G.; Wang, X. L.; Tan, R. X. Selesconol, a fungal polyketide that induces stem cell differentiation. Organic Letters 2016, 18, 5488. [CrossRef] [PubMed]

${ }^{55}$ Liu, W. C.; Yang, F.; Zhang, R.; Shi, X.; Lub, X. H.; Luan, Y. X.; Xiua, Z. L.; Dong, Y. S. Production of polyketides with anthelmintic activity by the fungus Talaromyces wortmannii using one strainmany compounds (OSMAC) method. Phytochemistry Letters 2016a, 18, 157. [CrossRef]

${ }^{56}$ Cheng, M. -J.; Chan, H. -Y.; Cheng, Y. -C.; Wu, M. -D.; Chen, J. -J.; Chen, Y. -L.; Hsieh, S. - Y.; Yuan, G. - F.and Su, Y. $-\mathrm{S}$. A new pyrrole metabolite from the endophytic fungus of Xylaria papulis. Chemistry of Natural Compounds 2015, 51, 515. [CrossRef] ${ }^{57}$ Ebada, S. S.; Eze, P.; Okoye, F. B. C.; Esimone, C. O.; Proksch, P. The fungal endophyte Nigrospora oryzae produces quercetin monoglycosides previously known only from plants. Chemistry Select 2016, 1, 2767. [CrossRef]

${ }^{58}$ Daengrot, C.; Rukachaisirikul, V.; Tadpetch, K.; Phongpaichit, S.; Bowornwiriyapan, K.; Sakayaroj, J.; Shen, X. Penicillanthone and penicillidic acids $A-C$ from the soil-derived fungus Penicillium PSU-RSPG105. RSC Advances 2016, 6, 39700. [CrossRef]

${ }^{59}$ Xiao, Z.; Chen, S.; Cai, R.; Lin, S.; Hong, K.; She, Z. New furoisocoumarins and isocoumarins from the mangrove endophytic fungus Aspergillus sp. 085242. Beilstein Journal of Organic Chemistry 2016, 12, 2077. [CrossRef] [PubMed]

${ }^{60}$ Macheleidt, J.; Mattern, D. J.; Fischer, J.; Netzker, T.; Weber, J.; Schroeckh, V.; Valiante, V.; Brakhage, A. A. Regulation and Role of Fungal Secondary Metabolites. Annual Review of Genetics 2016, 50, 16.1. [CrossRef] [PubMed]

${ }^{61} \mathrm{Du}$, L.; King, J. B.; Cichewicz, R.H. Chlorinated polyketide obtained from a Daldinia sp. treated with the epigenetic modifier suberoylanilide hydroxamic acid.
Journal of Natural Products 2014, 77, 2454. [CrossRef] [PubMed]

${ }^{62}$ Koehn, F. E. Biosynthetic medicinal chemistry of natural product drugs. Med. Chem. Commun., 2012, 3, 854. [CrossRef]

${ }^{63}$ Fujita, E.; Inoue, K.; Yamamoto, S.; Ikumoto, T.; Sasaki, S.; Toyama, R.; Chiba, K. Hoshino, Y. and Okumoto, T. Fungal metabolites. Part 11. A potent immunosuppressive activity found in Isaria sinclairii metabolite. The Journal of antibiotics, 1994, 47, 208. [CrossRef] [PubMed]

${ }^{64}$ Brunkhorst, R.; Vutukuri, R.; Pfeilschifter, W. Fingolimod for the treatment of neurological diseases - state of play and future perspectives. Frontiers in Cellular Neuroscience 2014, 8, 283. [CrossRef] [PubMed]

${ }^{65}$ Chun, J. M. D.; Brinkmann, V. A. Mechanistically Novel, First Oral Therapy for Multiple Sclerosis: The Development of Fingolimod (FTY720, Gilenya). Discovery Medicine 2011, 64, 213. [PubMed]

${ }^{66}$ Pietrangelo, A.; Higuera, V. Medically Multiple Sclerosis by the Numbers: Facts, Statistics, and you. Disponível em: <http://www.healthline.com/health/multiple -sclerosis/facts-statistics-

infographic\#overlayPassive>. Acesso em 06/03/2017. [Link]

${ }^{67}$ Guo, F. X.; Shi-Jin, E.; Liu, S. A.; Chen, J.; Li, D. C. Purification and characterization of a thermostable MnSOD from the thermophilic fungus Chaetomium thermophilum. Mycologia 2008, 100, 375. [PubMed]

${ }^{68}$ Dhakar, K.; Pandey, A. Wide $\mathrm{pH}$ range tolerance in extremophiles: towards understanding an important phenomenon for future biotechnology. Applied microbiology and biotechnology 2016, 100, 2499. [CrossRef] [PubMed]

${ }^{69}$ Fan, Z.; Sun, Z. -H.; Liu, Z.; Chen, Y. -C.; Liu, H. -X.; Li, H. -H.; Zhang, W. -M. Dichotocejpins A-C: New diketopiperazines from a deep-seaderived fungus Dichotomomyces cejpii FS110. Marine Drugs 2016, 14, 164. [CrossRef] [PubMed]

${ }^{70}$ Gunde-Cimerman N.; Zalar P.; de Hoog S.; Plemenitaš $A$. Hypersaline waters in salterns 
- natural ecological niches for halophilic black yeasts. FEMS Microbiology Ecology 2000, 32, 235. [PubMed]

${ }^{71}$ Le Calvez, T.; Burgaud, G.; Mahé, S.; Barbier, G.; Vandenkoornhuyse, P. Fungal diversity in deep-sea hydrothermal ecosystems. Applied and Environmental Microbiology 2009, 75, 6415. [CrossRef] [PubMed]

${ }^{72}$ Gonçalves, V. N.; Cantrell, C. L.; Wedge, D. E.; Ferreira, M. C.; Soares, M. A.; Jacob, M. R.; Oliveira, F. S.; Galante, D.; Rodrigues, F.; Alves, T. M.; Zani, C. L.; Junior, P. A.; Murta, S.; Romanha, A. J.; Barbosa, E. C.; Kroon, E. G.; Oliveira, J. G.; Gomez-Silva, B.; Galetovic, A.; Rosa, C. A.; Rosa, L. H. Fungi associated with rocks of the Atacama Desert: taxonomy, distribution, diversity, ecology and bioprospection for bioactive compounds. Environmental microbiology 2016, 18, 232. [CrossRef] [PubMed]

${ }^{73}$ Gunde-Cimerman, N.; Sonjak, S.; Zalar, P.; Frisvad, J. C.; Diderichsen, B.; Plemenitaš, A. Extremophilic fungi in arctic ice: a relationship between adaptation to low temperature and water activity. Physics and Chemistry of the Earth, Parts $A / B / C$ 2003, 28, 1273. [CrossRef]

${ }^{74}$ de Menezes, G. C. A. ; Godinho, V. M.; Porto, B. A. ; Gonçalves, V. N.; Rosa, L. H. Antarctomyces pellizariae sp. nov., a new, endemic, blue, snow resident psychrophilic ascomycete fungus from Antarctica. Extremophiles (Tokyo. Print) 2016, 1, 1. [CrossRef] [PubMed]

${ }^{75}$ Takahashi, J. A.; Lucas, E. M. F. Ocorrência e diversidade estrutural de metabólitos fúngicos com atividade antibiotica. Quimica Nova 2008, 31, 1807. [CrossRef]

${ }^{76}$ Fill, T. P.; Pallini, H. F.; Amaral, L. S.; Silva, J. V.; Bidóia, D. L.; Peron, F.; Garcia, F. P.; Nakamura, C. V.; Rodrigues-Filho, E. Copper and manganese cations alter secondary metabolism in the fungus Penicillium brasilianum. Jounal of the Brazillian Chemical Society 2016, 27, 1444. [CrossRef]

${ }^{77}$ Robbins, N.; Spitzer, M.; Wang, W.; Waglechner, N.; Patel, D. J.; O'Brien, J. S.; Ejim, L.; Ejim, O.; Tyers, M.; Wright, G. D. Discovery of ibomycin, a complex macrolactone that exerts antifungal activity by impeding endocytic trafficking and membrane function. Cell Chemical Biology 2016, 23, 1. [CrossRef] [PubMed]

${ }^{78}$ Yang, J.; Liang, Q.; Wang, M.; Jeffries, C.; Smithson, D.; Tu, Y.; Boulos, N.; Jacob, M. R.; Shelat, A. A.; Wu, Y.; Ravu, R. R.; Gilbertson, R.; Avery, M. A.; Khan, I. A.; Walker, L. A.; Guy, R. K.; Li, X. -C. UPLC-MS-ELSD-PDA as a powerful dereplication tool to facilitate compound identification from small-molecule natural product libraries. Journal of Natural Products 2014, 77, 902. [CrossRef] [PubMed] ${ }^{79}$ Klitgaard, A.; Iversen, A.; Andersen, M. A.; Larsen, T. O.; Frisvad, J. C.; Nielsen, K. F. Aggressive dereplication using UHPLC-DADQTOF: screening extracts for up to 3000 fungal secondary metabolites. Analytical Bioanalytical Chemistry 2014, 406, 1933. [CrossRef] [PubMed]

${ }^{80}$ Hanson, J. R. The microbiological transformation of diterpenoids. Natural Product Reports 1992, 9, 139. [CrossRef] [PubMed]

${ }^{81}$ Aleu J.; Collado, I. G. Biotransformations by Botrytis species. Journal of Molecular Catalysis B: Enzymatic 2001, 13, 77. [CrossRef]

${ }^{82}$ Turner, M. K. Em Perspectives in Biotransformations; Rehm, H.-J.; Reed G., eds., Wiley-Verlag: Weinheim, 1998, cap. 1. [CrossRef]

${ }^{83}$ Peterson, D. H.; Murray, H. C. Microbiological oxygenation of steroids at carbon 11. Journal of the American Chemical Society 1952, 74, 1871. [CrossRef]

${ }^{84}$ Donova, M. V.; Egorova, O. V. Microbial steroid transformations: current state and prospects. Applied Microbiology and Biotechnology 2012, 94, 1423. [CrossRef] [PubMed]

${ }^{85}$ Faber, K.; Biotransformations in Organic Chemistry, 6a. ed., Springer: New York, 2011. [Link]

${ }^{86}$ Fraga, B.; Bressa, C.; González-Vallejo, V.; González, P.; Guillermo, R. Biotransformation of ent-kaur-16-ene and ent-trachylobane $7 \beta$ acetoxy derivatives by the fungus Gibberella fujikuroi (Fusarium fujikuroi). Phytochemistry 2012a, 81, 60. [CrossRef] [PubMed]

${ }^{87}$ Hedden, P.; Sponsel, V. A century of gibberellin research. Journal of Plant Growth 
Regulation 2015, 34, 740. [CrossRef] [PubMed]

${ }^{88}$ Fraga, B.; Guillermo, R.; Hernández, M. G.; Chamy, M. C.; Garbarino, J. A. The incubation of 13 $\alpha, 17$-dihydroxystemodane with Cephalosporium aphidicola. Molecules 2012b, 17, 1744. [CrossRef] [PubMed]

${ }^{89}$ Zhan, Y.; Liu, H.; Wu, Y.; Wei, P.; Chen, Z.; Williamson, J. S. Biotransformation of artemisinin by Aspergillus niger. Applied Microbiology Biotechnology 2015, 99, 3443. [CrossRef] [PubMed]

${ }^{90}$ Chen, G.; Ge, H.; Song, Y.; Li, J.; Zhai, X.; $\mathrm{Wu}$, J.; Ling, X. Biotransformation of 20(S)protopanaxatriol by Mucor racemosus and the anti-cancer activities of some products. Biotechnology Letters 2015a, 27, 2005. [CrossRef] [PubMed]

${ }^{91}$ Nunes, F. M.; dos Santos, G. F.; Saraiva, N. N.; Trapp, M. A.; de Mattos, M. C.; Oliveira, M. C. F.; Rodrigues-Filho, E. New fungi for whole-cell biotransformation of carvone enantiomers. Novel p-menthane-2,8,9-triols production. Applied Catalysis A: General 2013, 468, 88. [CrossRef]

92 Bhatti, H. N.; Khan, S. S.; Khan, A.; Rani, M.; Ahmad, V. U.; Choudhary, M. U. Biotransformation of monoterpenoids and their antimicrobial activities. Phytomedicine 2014, 21, 1597. [CrossRef] [PubMed]

${ }^{93}$ Ascari, J.; Boaventura, M. A. D.; Takahashi, J. A.; Durán-Patrón, R.; Hernández-Galán, R.; Macías-Sánchez, A. J.; Collado, I. G. Biotransformation of bioactive isocaryolanes by Botrytis cinerea. Journal of Natural Products 2011, 74, 1707. [CrossRef]

${ }^{94}$ Xu, F.; Liao, K.; Liu, Y.; Zhang, Z.; Guo, D.; Su, Z.; Liu, B. Biotransformation of patchoulol by Cunninghamella echinulata var. elegans. Fitoterapia 2016, 109, 201. [CrossRef] [PubMed]

${ }^{95}$ Chen, L.-X.; Zhao, Q.; Zhang, M.; Liang, Y.Y.; Ma, J.-H.; Zhang, X.; Ding, L.-Q.; Zhao, F.; Qiu, F. Biotransformation of curcumenol by Mucor polymorphosporus. Journal of Natural Products 2015b, 78, 674. [CrossRef] [PubMed]

${ }^{96}$ Taveepanich, S.; Muangsin, N.; Saithong, S.; Pakawatchai, C.; Chaichit, N.; Roengsumran, S.; Petsom, A. Biotransformation of ent-kaur- 16-en-19-oic acid by Absidia blakesleeana and Rhizopus oligosporus. Natural Products Reports 2010, 24, 1050. [CrossRef] [PubMed] ${ }^{97}$ Hanson, J. R.; Hitchcock, P. B.; Takahashi, J. A. Biotransformation of ent-16 $\beta, 19-$ dihydroxykaurane by Cephalosporium aphidicola. Phytochemistry 1995, 40, 797. [CrossRef]

${ }^{98}$ Fraga, B. M.; Gonzalez, P.; Hernandez, M. G. J.; Suárez, S. Biotransformation of 7-oxoent-kaur-16-ene derivatives by Gibberella fujikuroi. Tetrahedron 2005, 61, 5623. [CrossRef]

${ }^{99}$ Liu, Z.; Lu, Y. H.; Feng, X.; Zou, Y. X.; Diao, Z.; Chu, Z. -Y. Microbial transformation of hederagenin by Cunninghamella echinulate, Mucor subtilissimus, and Pseudomonas oleovorans. Journal of Asian Natural Products Research 2016b, in press. [CrossRef] [PubMed]

100100 Martinez, A.; Rivas, F.; Perojil, A.; Parra, A.; Garcia-Granados, A.; Fernandez-Vivas, A. Biotransformation of oleanolic and maslinic acids by Rhizomucor miehei. Phytochemistry 2013, 94, 229. [CrossRef] [PubMed]

${ }^{101}$ Baydoun, E.; Wahab, A.-T.; Shoaib, N.; Ahmad, M. S.; Abdel-Massih, R.; Smith, C.; Naveed, N.; Choudhary, M. I. Microbial transformation of contraceptive drug etonogestrel into new metabolites with Cunninghamella blakesleeana and Cunninghamella echinulata. Steroids 2016, 115, 56. [CrossRef] [PubMed]

${ }^{102}$ Gomes, D. C.; Takahashi, J. A. Sequential fungal fermentation-biotransformation process to produce a red pigment from sclerotiorin. Food Chemistry 2016, 210, 355. [CrossRef] [PubMed]

${ }^{103}$ Shang, Z.; Salim, A. A.; Khalil, Z.; Bernhardt, P. V.; Capon, R. J. Fungal biotransformation of tetracycline antibiotics. The Journal of Organic Chemistry 2016, 81, 6186. [CrossRef]

${ }^{104}$ Han, F.; Lee, I. S. Microbial transformation of bavachin by Absidia coerulea. Phytochemistry Letters 2016, 18, 136. [CrossRef]

${ }^{105}$ Luo, J. M.; Liang, Q. K.; Shen, Y. B.; Chen, X.; Yin, Z. N.; Wang, M. Biotransformation of bavachinin by three fungal cell cultures. 
Journal of Bioscience Bioengineering 2014, 117, 191. [CrossRef] [PubMed]

${ }^{106}$ Zikmundová, M.; Drandarov, K.; Bigler, L.; Hesse, M.; Werner, C. Biotransformation of 2-benzoxazolinone and 2-hydroxy-1,4benzoxacin-3-one by endophytic fungi isolated from Aphelandra tetragona. Applied and Environmental Microbiology 2002, 68, 4863. [CrossRef] [PubMed] ${ }^{107}$ Zheng, Y.; $\mathrm{Xu}, \quad \mathrm{X}$;; Zou, X. Biotransformation of caffeine in oolong tea by Paecilomyces gunnii. International Biodeterioration \& Biodegradation 2016, 114, 141. [CrossRef]

${ }^{108}$ de Carvalho, C. C. C. R. Whole cell biocatalysts: essential workers from nature to the industry. Microbial Biotechnology 2017, 10, 250. [CrossRef] [PubMed]

${ }^{109}$ Patel, R. N. Biocatalysis: Synthesis of key intermediates for development of pharmaceuticals. ACS Catalysis 2011, 1, 1056. [CrossRef] [PubMed]

110110 Vespermann, K. A. C.; Paulino, B. N.; Barcelos, M. C. S.; Pessôa, M. G.; Pastore, G. M.; Molina, G. Biotransformation of $\alpha$ - and $\beta$ pinene into flavor compounds. Applied Microbiology and Biotechnology 2017, 101, 1805. [CrossRef] [PubMed]

${ }^{111}$ Mori, T.; Wang, J.; Tanaka, Y.; Nagai, K.; Kawagishi, H.; Hirai, H. Bioremediation of the neonicotinoid insecticide clothianidin by the white-rot fungus Phanerochaete sordida. Journal of Hazardous Materials 2017, 321, 586. [CrossRef] [PubMed]

${ }^{112}$ Marco-Urrea, E.; García-Romera, I.; Aranda, E. Potential of non-ligninolytic fungi in bioremediation of chlorinated and polycyclic aromatic hydrocarbons. New Biotechnology 2015, 32, 620. [CrossRef] [PubMed]

${ }^{113}$ Kao, C. M.; Lin, B. H.; Chen, S. C.; Wei, S. F.; Chen, C. C.; Yao, C. L.; Chien, C. C. Biodegradation of trinitrotoluene (TNT) by indigenous microorganisms from TNT contaminated soil, and their application in TNT bioremediation. Bioremediation Journal 2016, 20, 165. [CrossRef]

${ }^{114}$ Martins, L. R.; Lyra, F. H.; Rugani, M. M. H.; Takahashi, J. A. Bioremediation of metallic ions by eight Penicillium species. Journal of
Environmental Engineering 2015, 142.

[CrossRef]

${ }^{115}$ Espinosa-Ortiz, E. J.; Rene, E. R.; Pakshirajan, K.; Hullebusch, E. D. V., Lens, P .N. L. Fungal pelleted reactors in wastewater treatment: Applications and perspectives. Chemical Engineering Journal 2016, 283, 553. [CrossRef]

${ }^{116}$ Parameswari, E.; Lakshmanan, A.; Thilagavathi, T. Biosorption and metal tolerance potential of filamentous fungi isolated from metal polluted ecosystem. Electronic Journal of Environmental, Agricultural and Food Chemistry 2010, 9, 664. [CrossRef] [PubMed]

${ }^{117}$ Gaur, N.; Flora, G.; Yadav, M.; Tiwari, A. A review with recent advancements on bioremediation-based abolition of heavy metals. Environmental Science: Processes \& Impacts 2014, 16, 180. [CrossRef] [PubMed] ${ }^{118}$ Akar, T.; Tunali, S. Biosorption characteristics of Aspergillus flavus biomass for removal of $\mathrm{Pb}$ (II) and $\mathrm{Cu}$ (II) ions from an aqueous solution. Bioresource Technology 2006, 97, 1780. [CrossRef] [PubMed]

${ }^{119}$ Kapoor, A; Viraraghavan, T. BiosorptionAn Alternative treatment option for heavy metal bearing wastewaters: A Review. Bioresource Technology 1995, 53, 195. [CrossRef]

${ }^{120}$ Iram, S.; Shabbir, R.; Zafar, H., Javaid, M. Biosorption and bioaccumulation of copper and lead by heavy metal-resistant fungal isolates. Arabian Journal for Science and Engineering 2015, 40, 1867. [CrossRef]

${ }^{121}$ Netpae, T. $\mathrm{Cd}^{2+}$ Biosorption by pretreatment biomass of highly cadmium resistant fungus Humicola sp. Electronic Journal of Biology 2015, 11, 13. [Link]

122 Hassan, S. W.; El-Kassas, H. Y. Biosorption of cadmium from aqueous solutions using a local fungus Aspergillus cristatus. African Journal of Biotechnology 2012, 11, 2276. [CrossRef]

${ }^{123}$ Vacondio, B.; Birolli, W. G.; Ferreira, I. M.; Seleghim, M. H. R.; Gonçalves, S.; Vasconcellos, S. P.; Porto, A. L. M. Biodegradation of pentachlorophenol by marine-derived fungus Trichoderma harzianum CBMAI 1677 isolated from ascidian Didemnun ligulum. Biocatalysis and 
Agricultural Biotechnology 2015, 4, 266. [CrossRef]

${ }^{124}$ Phatake, Y. B.; Marathe, R. J.; Shejul, M. S. Use of fungi isolated from textile effluent for degradation of synthetic dyes and optimization of degradation process. Global Journal of Bio Sciences and Biotechnology 2015, 4, 314. [Link]

${ }^{125}$ Sogorb, M. A.; Vilanova, E. Enzymes involved in the detoxification of organophosphorus, carbamate and pyrethroid insecticides through hydrolysis. Toxicology Letters 2002, 128, 215. [CrossRef] [PubMed]

${ }^{126}$ Taştan, B. E.; Dönmez, G. Biodegradation of pesticide triclosan by $A$. versicolor in simulated wastewater and semi-synthetic media. Pesticide Biochemistry and Physiology 2015, 118, 33. [CrossRef] [PubMed]

${ }^{127}$ Ruiz-Hidalgo, K.; Chin-Pampillo, J. S.; Masís-Mora, M.; Carazo, E. R.; RodríguezRodríguez, C.E. Degradation of carbofuran by Trametes versicolor in rice husk as a potential lignocellulosic substrate for biomixtures: From mineralization to toxicity reduction. Process biochemistry 2014, 49, 2266. [CrossRef]

${ }^{128}$ Kumar, S. V. P.; Manjunatha, B. K.; Bhat, P.; Veena, R.; Pawate, S. S.; Yogashree, M. Bioremediation of poly aromatic hydrocarbons (pahs) and crude oil by fungal consortium from west coast of Karnataka, India. International Journal of Current Microbiology and Applied Sciences 2016, 5, 386. [CrossRef]
${ }^{129}$ Hadibarata, T.; Kristanti, R. A.; Hamdzah, $M$. Biosorption and biotransformation of fluoranthene by the white-rot fungus Pleurotus eryngii F032. Biotechnology and Applied Biochemistry 2014, 61, 126. [CrossRef] [PubMed]

${ }^{130}$ Ali, N.; Hameed, A., Ahmed, S. Role of brown-rot fungi in the bioremoval of azo dyes under different conditions. Brazilian Journal of Microbiology 2010, 41, 907. [CrossRef]

${ }^{131}$ Rani, K.; Dhania, G. Bioremediation and biodegradation of pesticide from contaminated soil and water - A noval Approach. International Journal of Current Microbiology and Applied Sciences 2014, 3, 23. [Link]

132 Jasińska, A.; Paraszkiewicz, K.; Sip, A.; Długoński, J. Malachite green decolorization by the filamentous fungus Myrothecium roridum- Mechanistic study and process optimization. Bioresource Technology 2015, 194, 43. [CrossRef] [PubMed]

${ }^{133}$ Mukherjee, P.; Roy, M.; Mandal, B. P.; Dey, G. K.; Mukherjee, P. K.; Ghatak, J.; Tyagi, A. K.; Kale, S. P. Green synthesis of highly stabilized nanocrystalline silver particles by a non-pathogenic and agriculturally important fungus T. asperellum. Nanotechnology 2008, 19, 75103. [CrossRef] [PubMed]

${ }^{134}$ Dhillon, G. S.; Brar, S. K.; Kaur, S.; Verma, $M$. Green approach for nanoparticle biosynthesis by fungi: current trends and applications. Journal Critical Reviews in Biotechnology 2012, 32, 49. [CrossRef] [PubMed] 